\title{
Lot Synchronization in Make-to-Order Shops with Order Release Control: An Assessment by Simulation
}

\author{
Nuno O. Fernandes ${ }^{1}$, Matthias Thürer, Mark Stevenson, Sílvio Carmo-Silva
}

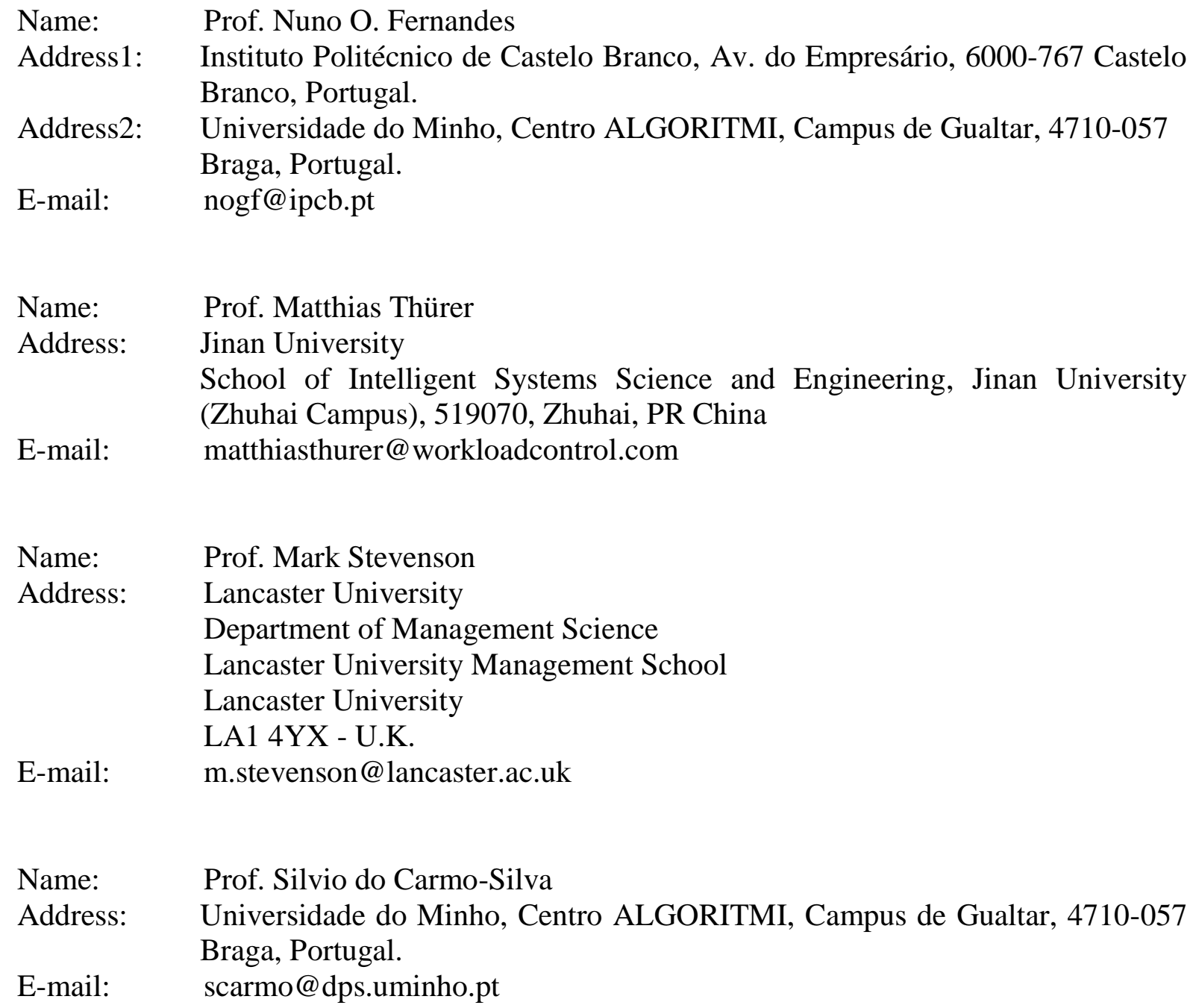

${ }^{1}$ Corresponding Author 


\title{
Lot Synchronization in Make-to-Order Shops with Order Release Control: An Assessment by Simulation
}

\begin{abstract}
Lot splitting is an important strategy for avoiding the starvation of workstations, for accelerating the progress of jobs, and ultimately for improving overall due date performance. While lot splitting has received much attention in the extant literature, the use of alternative lot transfer policies that determine how the flow of lots through the production system is synchronized has been largely neglected. This study uses simulation to assess the performance of different lot synchronization policies at release and different lot transfer policies on the shop floor in a ConWIP (Constant Work-In-Process) controlled job shop. The results suggest that different approaches should be applied at the release and shop floor levels. While lots should be synchronized in some form at order release, their progress on the shop floor should not be synchronized. Instead, lot coordination should be executed by dispatching in accordance with repetitive lots logic. The results further highlight that if lot progress is synchronized in systems that limit the workload, then lot release should also be synchronized. Otherwise, blocking may occur if lot progress on the shop floor depends on the release of lots, which in turn depends on lot progress. These findings have important implications for research and practice.
\end{abstract}

Keywords: Lot Splitting; Lot Release Policy; Lot Transfer Policy; ConWIP; Make-to-Order. 


\section{Introduction}

Lot splitting is an important manufacturing strategy for improving order progress and making better use of capacity, not only when orders are released to the shop floor immediately (e.g. Wagner \& Ragatz, 1994; Litchfield \& Narasimhan, 2000), but also when their release is controlled (e.g. Russell \& Fry 1997; Aglan \& Durmusoglu, 2015; Fernandes et al., 2016; Thürer et al., 2018). More specifically, lot splitting avoids starvation at downstream stations (Calleja \& Pastor, 2014), allows job progress to be accelerated, and improves delivery performance (Jacobs \& Bragg, 1988; Wagner \& Ragatz, 1994). As a result, there is a broad literature on lot splitting (Smunt et al., 1996; Jeong et al., 1999; Chang \& Chiu, 2005; Buscher \& Shen, 2009; Azzi et al., 2012; Cheng et al., 2013; Lalitha et al., 2017). This body of work pays attention to some important aspects such as lot sizing, but it pays insufficient attention to others, most notably lot transfer policies. This is partly explained by a focus in much of the extant literature on deterministic scheduling. In this context, lot synchronization is part of the scheduling problem. Deterministic scheduling however assumes the absence of uncertainty, which is not the case in real systems. Scheduling in stochastic environments usually requires buffering in time and quantity (Gaalman \& Perona, 2002). In this context, the lot transfer policy determines when a lot can proceed to the next station, and therefore also defines how the flow of lots (that make up a job) is synchronized through the production system. While there exists some literature on lot splitting in make-to-order contexts (e.g. Jacobs \& Bragg, 1988; Wagner \& Ragatz, 1994, Smunt et al., 1996; Azzi et al., 2012; Fernandes et al., 2016), most studies do not specify how lot transfers are managed; hence, this remains an important gap in the extant literature that is worthy of further research.

To the best of our knowledge, only two studies have explicitly taken the impact of the lot transfer policy into account: Kher et al. (2000) and Thürer et al. (2018). Kher et al. (2000) introduced a policy that synchronizes lots at each routing step. This policy only allows a lot to progress to the next station if all of the lots that make up the job have been completed. The only exception to this is if a downstream station is starving. Where a downstream station is starving, a lot can be pulled forward to avoid wasted capacity downstream. Based on a simulation of a pure flow shop, Kher et al. (2000) observed no significant performance improvements in terms of the throughput time or tardiness, but there were significant gains in terms of the number of lot transfers and lot integrity compared to allowing lots to progress freely through the system. Kher et al. (2000) defined lot integrity as the extent to which the lots that comprise a job physically stay together, i.e. the integrity of a lot is preserved when all of the transfer lots are moved together. Meanwhile, Thürer et al. (2018) showed that not 
synchronizing lots improves performance when compared to various lot transfer policies in high-variety shops, but the authors did not consider the policy proposed in Kher et al. (2000). Kher et al.'s (2000) study however was conducted in the context of a pure flow shop, where all jobs visit all stations in the same sequence. Moreover, order release was not controlled, i.e. all jobs could be released immediately onto the shop floor. In contrast, make-to-order shops, which are arguably in most need of lead time improvement, typically exhibit much higher degrees of routing complexity and benefit from the use of order release control. It therefore follows that there is a need to build on these two studies, determining how transfer policies perform in high-variety make-to-order environments, and how they interact with controlled order release.

If order release control is applied, then jobs are not directly released onto the shop floor but retained in a pre-shop pool (e.g. Land et al., 2014; Cransberg et al., 2016; Fernandes et al., 2016). Fernandes et al. (2016) recently showed that when order release control is applied, then enforcing synchronization at release, i.e. releasing all of the lots that make up a job together into the system, is a better policy than releasing lots individually at different release times. The authors did not however consider different lot transfer policies to coordinate lots on the shop floor. Instead, they allowed lots to progress independently through the shop. In general, and to the best of our knowledge, there has been no prior research on the interplay between the synchronization policy at release and the lot transfer policy on the shop floor.

This study seeks to provide guidance on which synchronization policy to apply at order release and on which transfer policy to apply on the shop floor. Simulation is employed to evaluate their use in a pure job shop to identify how best to take advantage of lot splitting in these contexts.

The remainder of this paper is structured as follows. In Section 2, we review the relevant literature before the simulation model used to evaluate performance is described in Section 3. The results are presented, analyzed, and discussed in Section 4 before conclusions are presented in Section 5.

\section{Background}

It is not our objective to comprehensively review the literature on lot splitting; for this, the reader is referred to Chang \& Chiu (2005) and Cheng et al. (2013). Rather, Section 2.1 briefly reviews the main studies relevant to the context of our research. Section 2.2 then discusses transfer policies from the literature and introduces the research questions that motivate our paper. 


\subsection{Literature Review: Lot-Splitting}

It has long since been demonstrated that lot splitting allows job progress to be accelerated and job due date performance to be improved (Jacobs \& Bragg, 1988; Wagner \& Ragatz, 1994). This effect however is dependent on a variety of factors. For example, Karmarkar et al. (1985) argued that an increase in set-up times may outweigh any reduction in throughput times obtained from lot splitting. Lockwood et al. (2000) however concluded that additional set-ups before the bottleneck may improve due date performance without affecting the average throughput time of jobs. Meanwhile, several heuristic procedures have been proposed and applied to determine the most appropriate lot size (see, e.g. Jeong et al., 1999; Buscher \& Shen, 2009; Azzi et al., 2012). Kropp \& Smunt (1990) concluded however that simply using equalsized lots works well in many situations. Moreover, Smunt et al. (1996) investigated various lot splitting policies in both stochastic job shop and flow shop environments finding that the number of lot splits is more important than the exact form of lot splitting.

Another research stream has focused on lot splitting in the context of controlled job release (see, e.g. Russell \& Fry, 1997; Aglan \& Durmusoglu, 2015; Fernandes et al., 2016; Thürer et al., 2018). Russell \& Fry (1997) assessed the impact of lot splitting in a Drum-Buffer-Rope (DBR) controlled V-plant. Meanwhile, Aglan \& Durmusoglu (2015) sought to identify optimum sublot sizes in a ConWIP controlled cellular production layout, where cellular and functional layouts are combined. Finally, Fernandes et al. (2016) and Thürer et al. (2018) highlighted the potential of lot splitting to improve performance in the context of Workload Control and the POLCA system (Paired Overlapping Loops of Cards with Authorization), respectively.

To the best of our knowledge, most of these studies did not specify the transfer policy applied. In contrast, the studies by Kher et al. (2000) and Thürer et al. (2018) focused explicitly on the transfer policy and lot integrity. These two studies will be further discussed next.

\subsection{Discussion of Transfer Policies from the Literature}

At the extremes, a lot transfer policy may either consider or not consider lot synchronization. When it is considered, there are two different views on synchronization (Chankov et al., 2016, 2018): (1) the flow-focused perspective, which originated in the manufacturing and logistics research domain and refers to the coupling of work systems that are linked by material flows; and, (2) the system-focused perspective, which originated in the natural sciences domain and refers to the rhythm and repetitive behaviour of production processes in a manufacturing system. In our study, the focus is on the flow of job lots between work systems (or stations) 
and therefore our definition of synchronization is aligned with the former view. That is, synchronization occurs when all lots of the same job are provided to the subsequent production step just-in-time. Consequently, if lot synchronization is enforced, then a lot must wait until all lots of the job are complete before it, together with all the others, can proceed to the next station. If lot synchronization is not enforced, then any lot can proceed freely after completion at a given station. A third, intermediate option that partially synchronizes lot transfers between stations was presented by Kher et al. (2000). The authors did not use full synchronization. Instead, they adopted a 'pull' approach that allows a lot to proceed to the next station - even if all lots of the job are not yet completed and thus fully synchronized - if the next station is starving. Thus, in total, three transfer policies can be identified:

- Transfer Policy 1 (synchronization): each lot that makes up a job must wait until all lots of the job are completed at a station before proceeding to the next station in the routing, and finally to the customer;

- Transfer Policy 2 (synchronization plus starvation avoidance): as for Policy 1, but a lot may proceed to the next station even if all lots of the job have not yet been completed if the next station is starving; and,

- Transfer Policy 3 (no synchronization): each lot of a job can proceed independently through the shop floor, but it must wait until all lots of a job have been completed before it can be delivered to the customer.

Policy 2 is inspired by the pull approach of Kher et al. (2000) and detailed in Section 3.2. In the context of the pure flow shop, where all jobs visit all stations in the same sequence, Kher et al. (2000) showed that the pull approach performs statistically equivalent in terms of throughput time and tardiness to Policy 3; however, the former leads to higher lot integrity. Meanwhile, Thürer et al. (2018) showed that when jobs have random routings, directed from upstream to downstream stations, as in general flow shops, Policy 3 is a better option than Policy 1. However, Thürer et al. (2018) did not consider Policy 2, while Kher et al. (2000) only evaluated the pull approach in a pure flow shop. The latter is a major shortcoming given that many of the shops that require lead time reduction are make-to-order shops characterized by high routing complexity. Our first research question therefore asks:

RQ1: What is the impact on performance of the alternative lot transfer policies in the context of high routing complexity? 
The transfer policy controls lot progress on the shop floor, but if order release control is applied then managers must decide how the release of individual lots that make up a job should be synchronized - the reduction of work-in-process itself does not create logistic synchronization (Chankov et al., 2018). Fernandes et al. (2016) recently showed that if order release control is applied then enforcing synchronization at release, i.e. releasing all of the lots that make up a job onto the shop floor together, is a better policy than releasing lots individually at different release times. This finding however seems to contradict the results in Thürer et al. (2018) on the lot transfer policy, which suggest that different approaches may be needed at release and on the shop floor. Fernandes et al. (2016) however did not consider different transfer policies on the shop floor, while Thürer et al. (2018) did not consider different synchronization policies at order release. There is thus a need to combine the insights from the two studies. Our second (and final) research question therefore asks:

RQ2: $\quad$ Should the release of lots be synchronized in addition to synchronizing their progress on the shop floor?

Controlled simulation experiments will be used to address our two research questions. The following section outlines the simulation model used in the study.

\section{Simulation}

A stylized standard model of a pure job shop is used in this study to avoid interactions that may otherwise interfere with our understanding of the main experimental factors. This kind of model is widely applied in the literature (e.g. Melnyk \& Ragatz, 1989; Land, 2006; Land et al., 2015; Fernandes et al., 2017; Thürer et al., 2018) allowing for the validation of our simulation model. While any individual shop in practice will differ from our stylized environment, the model used in this study capture the job and shop characteristics of high variety make-to-order shops, i.e. high routing variability, high processing time variability and high arrival time variability. The shop and job characteristics will be introduced in Section 3.1. Section 3.2 then summarizes the different lot transfer policies and the dispatching rule applied on the shop floor before Section 3.3 introduces the order release method. Finally, the experimental design and performance measures are outlined in Section 3.4.

\subsection{Overview of Modelled Shop and Job Characteristics}

A simulation model of a pure job shop has been implemented in ARENA ${ }^{\circledR}$ software. We chose the pure job shop since it exhibits low logistic synchronization (Chankov et al., 2018) and thus 
mostly relies on effective lot synchronization. We have kept our shop relatively small since this allows causal factors to be identified more easily. Small systems provide a better insight into the role of operating variables and, in practice, large systems can often be decomposed into several smaller systems (Bokhorst et al., 2004). At the same time, we selected a size that allows for comparison with previous studies that have investigated order release in job shop contexts. Thus, the shop contains six stations, where each is a constant and equal capacity resource.

Routings in the pure job shop are undirected and the routing length of jobs varies uniformly from one to six operations. The routing length is first determined before the routing sequence is generated randomly without replacement. The operation times of jobs follow a truncated 2Erlang distribution with a mean of 1 time unit and a maximum of 4 time units. Set-up times have been considered as part of the operation time and tested at two levels, namely at zero and five percent of the operation time. Set-up times are modelled by reducing the operation time by the set-up factor $(0 \%$ or $5 \%)$ if a lot from the job currently being processed is processed next at the same station.

Smunt et al. (1996) found that the number of lot splits is more important than the exact form of lot splitting. Therefore, we focus on this characteristic of lot splitting, considering three different splits: (i) all jobs consist of 2 lots; (ii) all jobs consist of 3 lots; and, (iii) all jobs consist of 4 lots. The lots that make up a job are of equal size, which is motivated by Kropp \& Smunt's (1990) finding that using equal-sized lots works well in many situations. This means that, for example, a job with an operation time of 3 time units has 1.5 time units per lot if the lot is split into two and 1 time unit per lot if the lot is split into three. Meanwhile, a scenario without splitting jobs was not considered since the focus of the study is on lot transfer policies.

The inter-arrival time of jobs follows an exponential distribution with a mean of 0.648 time units. This deliberately result in a utilization level of $89.2 \%$ at all stations when the set-up factor is $0 \%$, which has been the benchmark in many simulation studies (e.g. Land, 2006; Fernandes et al., 2016, 2017; Thürer et al., 2017, 2019). Due dates are set exogenously by adding a random allowance to the job entry time. This allowance is uniformly distributed between 30 and 50 time units. The lowest value of the allowance will be enough to cover a minimum shop floor throughput time corresponding to the maximum processing time of 4 time units for the maximum number of possible operations (i.e. six) plus an allowance for the waiting or queuing time. The maximum value was set arbitrarily such that the percentage tardy under immediate release is approximately $10 \%$. 


\subsection{Workflow Control on the Shop Floor}

The flow of work on the shop floor is controlled by a priority dispatching rule and a lot transfer policy. In this study, the repetitive lots logic of Jacobs \& Bragg (1988) is used for shop floor dispatching. According to this logic, whenever a station becomes available a lot of the same job as the one that has just been processed is selected from the queue directly feeding it. In the case that a lot of the same job is not available, the first-in-system-first-served (FIFS) rule proposed by Spearman et al. (1990) and Hopp \& Spearman (2001) is used to select the next lot. Lot progress is further restricted by the lot transfer policy (see Section 2.2 above for the three alternative policies). In the case of Transfer Policy 2 (synchronization plus starvation avoidance), the station attempts to pull a transfer lot from a feeding station whenever it becomes idle, i.e. when, after processing a lot, there are no more lots in the queue directly feeding the station. If there are multiple feeding stations, then the lot is pulled from the station with the longest queue. The FIFS rule is used as a 'tie-breaker' to select the lot to be pulled.

\subsection{Job Release Control}

We will use Constant Work-in-Process (ConWIP; e.g. Spearman et al., 1990; Hopp \& Spearman, 2001; Jaegler et al., 2018) to control order release. ConWIP is an order release system that can be used to supplement an MRP system (e.g. Zäpfel \& Missbauer 1993; Hopp \& Spearman, 2001) and has been widely applied in practice (e.g. Slomp et al., 2009; Prakash \& Chin, 2014; Crop et al., 2015; Leonardo et al., 2017; Olaitan et al., 2019). Under ConWIP, jobs are only permitted to enter the shop floor if a limit on the shop work-in-process (WIP) is not violated; otherwise, they must wait in the pre-shop pool until some of the jobs on the shop floor have been completed. ConWIP can be unit-based or load-based (Thürer et al., 2019), depending on whether feedback on the shop WIP represents the physical inventory or the level of workload on the shop floor. Therefore, two WIP measures are considered in the study, as follows:

- The number of lots: which is in accordance with the original ConWIP system; and

- The shop load: which represents the total workload in time units of all lots on the shop floor.

As in previous simulation studies on ConWIP (e.g. Hopp \& Spearman, 1991; Bonvik et al., 1997; Herer \& Masin, 1997; Jodlbauer \& Huber, 2008; Thürer et al., 2017), it is assumed that materials are available and all necessary information regarding the shop floor routing, e.g. operations times, is known upon the arrival of a job in the pool. On arrival, jobs directly enter the pool and await release according to ConWIP. 
Jobs in the pool are sequenced according to a capacity slack rule, as given by Equation (1), which was chosen based on its good performance in Thürer et al. (2017). The lower the capacity slack ratio $C S_{j}$ of job $j$, the higher the priority of the job.

$$
C S_{j}=\frac{\sum_{s \in S_{j}}\left(\frac{\frac{p_{j s}}{i}}{N_{S}^{c}-W_{s}^{c}}\right)}{n_{j}}
$$

The capacity slack ratio integrates three elements into one priority measure: the workload contribution of a job to a station, $\frac{p_{j s}}{i}$; the load gap $\left(N_{s}^{c}-W_{S}^{c}\right)$ at a station $s$ processing operation $i$ of job $j$; and the routing length $n_{j}$ (i.e., the number of operations in the routing of the job), which is used to average the ratio between the load contribution and the load gap elements over all operations in the routing of the job.

Previous literature considered two parameters for ConWIP, a limit on the WIP and a workahead window (Jodlbauer \& Huber, 2008; Hübl et al., 2011). In this study, an infinite workahead window will be applied, which means that all jobs in the backlog are eligible for release. This is justified by the negative performance impact - in terms of throughput time and tardiness - that has been observed from using a work-ahead window in previous research set in similar contexts to our research (e.g. Land, 2006). Meanwhile, five limit levels are applied: 30, 36, 42, 48, and 54. These limits are multiplied by the number of lots per job for the scenarios where the number of lots in the system is limited (the original ConWIP system), and by the mean operation time per job for the scenarios where the shop load, in time units, is limited. In addition, experiments with no limit on the shop WIP are also executed, referring to no order release control.

Three synchronization policies are applied for order release control, namely:

- Release Policy 1 (synchronization): where all lots of a job must be released together; and,

- Release Policy 2 (synchronization plus starvation avoidance): as for Policy 1, but a job may be pulled and released to the shop floor if the first station in the routing of the job is starving, even if the work-in-process limit is violated.

- Release Policy 3 (no synchronization): where each lot that makes up a job can be released independently. 


\subsection{Experimental Design and Performance Measures}

The experimental factors are summarized in Table 1. A full factorial design was used with 432 $(2 \times 2 \times 6 \times 2 \times 3 \times 3)$ scenarios. Each scenario was replicated 100 times and all results were collected over 13,000 time units following a warm-up period of 3,000 time units. These parameters allow us to obtain stable results while keeping the simulation run time to an acceptable level.

\section{[Take in Table 1]}

Since we focus on a high-variety make-to-order environment, our main performance indicator will be delivery performance, as is widely adopted in the related literature, e.g. Melnyk \& Ragatz (1989), Land (2006), Ziengs et al. (2012), Land et al., (2015), Fernandes et al. (2017), and Thürer et al. (2018). As for most make-to-order contexts in practice, there is no penalty on earliness. Delivery performance is therefore measured based on the percentage tardy, i.e. the percentage of jobs completed after the due date; and the mean tardiness, that is $T_{j}=$ $\max \left(0, L_{j}\right)$, with $L_{j}$ being the lateness of job $j$. We also measure the mean total throughput time, i.e. the mean of the completion date minus the pool entry date, across jobs. The mean lateness can be derived directly from this measure by subtracting the mean of the due date allowance from the mean total throughput time. Finally, in addition to the three main tardiness related performance measures, we also measure the average shop floor throughput time (i.e. the time that a job spends in the system after it has been released) and the average machine utilization rate.

\section{Results}

To assess performance differences between control polices, Section 4.1 below presents detailed performance results for the scenario where ConWIP measures WIP in terms of the number of lots, and the set-up factor is zero. The impact of the WIP measure applied at order release, and the impact of set-up times, is then explored in Section 4.2 to assess the robustness of our results. Finally, a discussion of the results is presented in Section 4.3.

The significance of the performance differences between the outcomes of individual experiments were verified by paired t-tests, which comply with the use of common random number streams to reduce variation across experiments. Whenever we discuss a difference in outcomes between two experiments, the significance can be proven by a paired t-test at a level of $95 \%$. 


\subsection{Performance Assessment: WIP Measured in Lots}

To aid interpretation, the simulation results are presented in the form of performance curves, while more detailed simulation results are also provided in an online supplement (see Appendix A). The left-hand starting point in each performance curve represents the tightest limit on the shop WIP. This limit increases stepwise by moving from left to right in each graph, with each data point representing one limit level. Increasing the limit level raises the shop WIP and, as a result, increases shop floor throughput times.

Figure 1 shows the total throughput time, the percentage tardy, and mean tardiness over the shop floor throughput time for the scenarios where jobs are split into 2 lots, into 3 lots, and into 4 lots. Only results for the situation where the set-up time factor is zero and using the number of lots as the WIP measure (as in the original ConWIP system) are shown in the figure. The impact of these two factors is assessed in our robustness analysis in Section 4.2.

\section{[Take in Figure 1]}

The following can be observed from the results:

- ConWIP control: ConWIP has the potential to improve performance compared to no order release control in terms of the total throughput time and percentage tardy whilst simultaneously reducing WIP and shop floor throughput times. However, the limit on the number of lots allowed on the shop floor must be set appropriately. This is because a tighter limit restricts the WIP and thus leads to shorter shop throughput times, as can be observed from Figure 1. Once the total throughput time is equal to the shop floor throughput time plus the pool time, a tighter limit also leads to a shorter total throughput time. However, if the limit on the number of lots is set excessively tight, waiting times in the pre-shop pool are not compensated for by the shorter throughput times on the shop floor, and thus the total throughput time increases. The limit level at which performance starts to deteriorate will depended on the workload balancing capabilities of the control strategy adopted.

- Release Policy: Release Policy 2 (synchronization plus starvation avoidance) maintains or improves performance compared to Release Policy 1 (synchronization), specifically at tighter limits on the number of lots allowed on the shop, through its starvation avoidance mechanism. At the tightest limit for the number of lots on the shop floor, the performance improvement for the percentage tardy is $9.2 \%, 2.7 \%$ and $3.5 \%$ when the number of lots per job is set to 2, 3, and 4, respectively and the transfer of lots on the shop floor is based on Policy 3. When the transfer of lots is based on Policy 2, these values are 9.9\%, 2.2\%, and 
$3.1 \%$, respectively; and when based on Policy 1 , these values are $10.5 \%, 4.3 \%$, and $4.9 \%$, respectively. Performance differences between these experiments, based on a paired t-test, for the tightest limit level are presented in Table 2. Meanwhile, results for Release Policy 3 are equivalent to those for Release Policy 1. This will be discussed further in Section 4.3 below.

- Lot Transfer Policy: Transfer Policy 3 (no synchronization) outperforms Transfer Policy 1 (synchronization) and Transfer Policy 2 (synchronization plus starvation avoidance). For example, at the tightest setting for the limit on the number of lots in the shop, the performance improvement over Transfer Policy 1 for the percentage tardy is $19.1 \%, 25.1 \%$, and $26.4 \%$ when the number of lots per job is set to 2,3 , and 4 , respectively and release is based on Policy 2. Under the same conditions, the performance improvement over Transfer Policy 2 is $16.1 \%, 21.7 \%$, and $22.2 \%$, respectively. Performance differences between these experiments, based on a paired t-test, for the tightest limit level are presented in Table 2. This finding can mainly be attributed to much shorter shop floor throughput times - as can be observed from the total throughput times - that result from the overlapping of operations between successive stations in the routing of jobs.

- Lot Splitting: Increasing the number of lots per jobs allows for performance improvements in terms of all three performance measures considered in this study. This is in line with previous studies, e.g. Altendorfer et al. (2013). Most performance gains however are already realized with three lots per job, hence there are only marginal gains to be had from increasing the number of lots per job to four.

[Take in Table 2]

\subsection{Robustness Analysis}

\subsubsection{WIP Measure}

To assess the impact of the Work-In-Process (WIP) measure applied, Figure 2 present the same performance measures as in Figure 1 but for the scenarios where the shop load rather than the number of lots is limited.

\section{[Take in Figure 2]}

Limiting the workload leads to a general performance improvement in terms of the percentage tardy since jobs with shorter operation times have a higher probability of being released to the shop floor than large jobs. This is because they better fit the limit on the 
workload imposed, i.e. a shortest operation time effect is created. Compared to Figure 1, the following can be observed:

- ConWIP Control: ConWIP again has the potential to improve performance compared to no order release control whilst reducing work-in-process and shop floor throughput times. The results however are much more sensitive to the workload limit applied when the workload is used as the measure of the shop WIP. The use of the workload measure facilitates the release of small jobs and hinders the release of large jobs compared to the original ConWIP system (that controls the number of lots). This leads to a shortest operation time effect, and thus to a higher mean tardiness.

- Release Policy: While Release Policy 2 (synchronization plus starvation avoidance) retains its performance gains in terms of the total throughput time and mean tardiness, compared to Release Policy 1 (synchronization), it is outperformed by Release Policy 1 in terms of the percentage tardy when WIP is measured by the shop workload. Meanwhile, Release Policy 3 has the potential to outperform Release Policy 2 but leads to unstable results at tighter workload limits, particularly under Transfer Policy 1 . Therefore, performance curves for Release Policy 3 do not contain markers for the tightest workload limit. Unstable results mean that a steady state is not reached since, at a certain moment in the simulation, jobs are no longer processed but accumulate in the pre-shop pool. This will be explained further in Section 4.3 below.

- Lot Transfer Policy: Transfer Policy 3 (no synchronization) outperforms Transfer Policy 1 (synchronization) and Transfer Policy 2 (synchronization plus starvation avoidance). While this can again be mainly attributed to shorter shop floor throughput times, there is also an increase in pool waiting times for transfer policies 1 and 2 at tight load limits.

- Lot Splitting: The positive performance effect observed when increasing the number of lots per job from two to four is less pronounced than the effect shown in Figure 1.

\subsubsection{Set-up Times}

Similar conclusions on the relative performance of experimental factors to those in the scenario with a set-up factor of zero can be drawn from the results for the scenario with a set-up factor of five percent. This can be observed from Figure 3 and Figure 4, which depict the results for the scenarios when the shop WIP is measured by the number of lots and by the shop load, respectively. The main difference is a general performance improvement in terms of time and tardiness related performance measures, particularly when splitting jobs into more lots, which can be explained by the lower utilization level realized. This can be seen from Table 3, which 
summarizes the realized utilization levels. If we compare the average utilization across transfer policies, then we observe slightly lower utilization levels for transfer policies 1 and 2. This is because enforcing synchronization while using repetitive lots logic necessarily minimizes setups. The lower utilization of these transfer policies however is not enough to outweigh the improved performance of Transfer Policy 3. While there is no synchronization in terms of lot transfer for Transfer Policy 3 (i.e. the movement from one queue to another), there is synchronization in terms of which job from the queue to process next, i.e. dispatching. The repetitive lots logic used at dispatching realizes a higher degree of lot synchronization in periods of high load for Transfer Policy 3 since lots wait longer in the queue, which increases the probability that lots of the same type accumulate in the same queue. Thus, additional capacity gains through set-up time reduction for Transfer Policy 1 and Transfer Policy 2 are lower in the periods when it is most important (Land et al., 2015). This may explain why previous studies indicated that the benefits of lot splitting are persistent even when faced with long set-ups (Kher et al., 2000).

[Take in Figure $3 \&$ Figure $4 \&$ in Table 3]

\subsection{Discussion of Results}

The research presented in this paper has been mainly motivated by three prior contributions to the literature: Kher et al. (2000), Fernandes et al. (2016), and Thürer et al. (2018). Kher et al. (2000) showed that, for the pure flow shop, only allowing individual lots to proceed to the next station if the downstream station is starving performs statistically equivalent to allowing lots to proceed independently through the shop floor. But rather than confirming Kher et al. (2000), our findings support and extend Thürer et al. (2018), which showed that allowing lots to proceed independently through the shop floor (Transfer Policy 3) is a better option than synchronizing their progress (Transfer Policy 1). Transfer Policy 3 led to the best results across all performance measures and all modelled scenarios.

A main explanatory variable is that in Transfer Policy 2 idle stations just pull a single transfer lot from a feeding station. The remaining lots of the job are not immediately transferred as they are processed at the feeding station. Instead, they are synchronized and transferred all together; the only exception to this is if the starving station remains idle after processing and therefore pulls another lot. While this may restrict the number of transfers incurred when compared to Policy 3, it leads to higher job throughput times as the transferred lot must wait for the remaining lots of the job to proceed to a further downstream station, with other jobs being processed in-between. This is emphasized by the routing configuration of the pure job 
shop that has a low level of logistic synchronization. In contrast, the pure flow shop, as used in Kher et al., (2000), has a high level of logistic synchronization (Chankov et al. 2018) since all jobs follow the same sequence, which explains the results in Kher et al. (2000).

Another important finding from our study is that, if some form of synchronization is enforced on the shop floor at stations, or only after all of the transfer lots belonging to a job have been processed, then synchronization at release is also required when a release mechanism that limits the shop WIP (such as ConWIP in our study) is applied. Release Policy 3 led to blocking under tight limits on the number of lots in the shop or to results that are equivalent to Release Policy 1 when the shop load, rather than the number of lots, is restricted. In our experiments, the number of ConWIP cards released back to the pool once a job has been completed is equal to the number of ConWIP cards needed to release all of the lots of a new job. Since the lots of a job share the same capacity slack value, all of the lots of a job are released together, even if no synchronization is applied. Hence, the results of Release Policy 3 are equivalent to those of Release Policy 1, i.e. full synchronization. If the number of lots per job was different across jobs and their release was not synchronized, then some of the lots that make up a job could potentially be released while others were left to remain in the pool. Similarly, if a workload limit is applied, then the workload released when one job is completed is not necessarily equal to the workload required by the lots of a job waiting in the pool. Hence, some of the lots of a job may be released, while others would continue to wait. If synchronization is applied on the shop floor, then lot progress depends on the lots in the pool also being released. Yet, at the same time, the release of lots from the pool is dependent on the progression of lots through the shop floor if the number of lots in the system is to continue to be controlled. As a consequence, blocking occurs. The risk and severity of this blocking phenomenon increases with the tightness of the WIP limit. This extends the findings in Fernandes et al. (2016), which recently showed that if order release control is applied then enforcing full synchronization at workload control release, i.e. releasing all of the lots that make up a job into the system together, is a better policy than releasing lots individually at different release times.

Enforcing some form of synchronization at order release is necessary to avoid blocking if some form of lot synchronization is applied on the shop floor. Synchronization plus starvation avoidance appears however to be a better solution at release than full synchronization in shops with random routings. It avoids the blocking effect that occurs with no synchronization whilst also avoiding premature station idleness, which is a characteristic of load-limiting order release methods (Kanet, 1988; Land \& Gaalman, 1998). 


\section{Conclusions}

Lot splitting is an important strategy to avoid starvation at downstream stations, to accelerate job progress, and to improve overall job due date performance. Consequently, a broad literature on lot splitting exists. The impact of the lot transfer policy that determines how the flow of lots that make up a job is synchronized through the production system has however received only limited attention. Moreover, in this limited literature, there is a lack of consensus. For example, while some studies have argued for lot synchronization on the shop floor, others have argued that not synchronizing lot progression is in fact a better strategy. One factor that may explain these apparently contradictory results is the routing characteristics underpinning the shop models.

In response to the above, we have asked two research questions. First: What is the impact on performance of the alternative lot transfer policies in the context of high routing complexity? Using simulation, we have shown that not synchronizing lot progress is the best solution if dispatching based on the repetitive lots logic is applied on the shop floor and that performance differences across lot synchronization policies are robust to set-up time considerations. Second: Should the release of lots be synchronized in addition to synchronizing the progress of lots on the shop floor? We have found that some form of synchronization is required at order release if lot progression is synchronized on the shop floor. Without synchronization at release, blocking may occur. This extends the results presented in the extant literature, which demonstrated that full synchronization at release outperforms no synchronization. However, our results also show that synchronization plus starvation avoidance of jobs has the potential to improve performance since it avoids premature station idleness.

\subsection{Managerial Implications}

The main managerial implication of our paper is that different approaches should be followed at order release and on the shop floor. While the release of lots to the shop floor should be synchronized in some form, the progress of lots once released to the shop floor should not be synchronized. Instead, a dispatching rule that ensures synchronization, such as based on repetitive lots logic, should be applied. Our study also further highlights the positive performance effects of ConWIP compared to no order release control. Yet, although limiting the workload instead of the number of lots improves performance, it also introduces a shortest operation time effect. Thus, managers must trade off percent tardy gains against losses in terms of the mean tardiness of jobs. 


\subsection{Limitations and Future Research}

A main limitation of our study is that we have only considered one release method: ConWIP. While this is justified by ConWIP's simplicity and the need to keep our study focussed, future research is required to confirm our findings under different release methods. For example, we have shown that synchronization combined with the pull release of jobs to the shop floor for starvation avoidance has the potential to outperform synchronization without pull release (as advocated by Fernandes et al. (2016), but this has not been tested in the context of more sophisticated approaches, such as Workload Control. More complex manufacturing environments and other shop configurations must also be investigated.

\section{Acknowledgments}

This work was supported by COMPETE: POCI-01-0145-FEDER-007043 and FCT-Fundação para a Ciência e Tecnologia within the Project Scope: UID/CEC/00319/2013; and by the National Natural Science Foundation of China (71750410694; 71872072), Guangdong Province Universities and Colleges Pearl River Scholar Funded Scheme 2017.

\section{References}

Aglan, C. and Durmusoglu, M.B., 2015, Lot-splitting approach of a hybrid manufacturing system under CONWIP production control: a mathematical model, International Journal of Production Research, 53, 5, 1561-1583.

Altendorfer, K., Felberbauer, T., Gruber, D., Hübl, A., (2013) Application of a generic simulation model to optimize production and workforce planning at an automotive supplier, In Proceedings of the 2013 Winter Simulation Conference: Simulation: Making Decisions in a Complex World (WSC '13). IEEE Press, Piscataway, NJ, USA, 2689-2697.

Azzi, A., Maurizio, F., and Persona, A., 2012, Lot Splitting Scheduling Procedure for Makespan Reduction and Machine Capacity Increase in a Hybrid Flow Shop with Batch Production, International Journal of Advanced Manufacturing Technology, 59, 5, 775-786.

Bokhorst, J.C.A., Slomp, J., and Gaalman G.J.C., 2004, On the who-rule in Dual Resource Constrained (DRC) manufacturing systems, International Journal of Production Research, $42,23,5049-5074$.

Bonvik, A.M., Couch, C.E. and Gershwin, S.B., 1997, A comparison of production-line control mechanisms, International Journal of Production Research, 35, 3, 789- 804. 
Buscher, U., and Shen, L., 2009, An Integrated Tabu Search Algorithm for the Lot Streaming Problem in Job Shops, European Journal of Operational Research, 199, 2, 385-399.

Calleja, G., and Pastor, R., 2014, A dispatching algorithm for flexible job-shop scheduling with transfer batches: an industrial application, Production Planning \& Control, 25, 2, 93-109.

Chang, J.H., and Chiu, H.N., 2005, A Comprehensive Review of Lot Streaming, International Journal of Production Research, 43, 8, 1515-1536.

Chankov, S.M., Huett, M. and Bendul, J., 2018, Influencing Factors of Synchronization in Manufacturing Systems, International Journal of Production Research, 56, 14, 4781-4801.

Chankov, S.M., Huett, M., and Bendul J.,2016, Synchronization in Manufacturing Systems: Quantification and Relation to Logistics Performance, International Journal of Production Research, 54, 20, 6033-6051.

Cheng, M., Mukherjee, N.J., and Sarin, S.C., 2013, A Review of Lot Streaming, International Journal of Production Research, 51, 23-24, 7023-7046.

Cransberg, V., Land M., Hicks, C. and Stevenson, M., 2016, Handling the complexities of reallife job shops when implementing workload control: A decision framework and case study, International Journal of Production Research, 54, 4, 1094-1109.

Crop, F., Lacornerie, T., Mirabel, X. and Lartigau, E., 2015 Workflow Optimization for Robotic Stereotactic Radiotherapy Treatments: Application of Constant Work in Progress Workflow, Operations Research for Health Care, 6, 1, 18-22.

Fernandes, N.O., Land, M.J., and Carmo-Silva, S., 2016, Aligning workload control theory and practice: lot splitting and operation overlapping issues, International Journal of Production Research, 54, 10, 2965-2975.

Fernandes, N.O., Thürer, M., Silva, C., Carmo-Silva, S., 2017, Improving workload control order release: Incorporating a starvation avoidance trigger into continuous release, International Journal of Production Economics, 194, 1, 181-189.

Gaalman, G.J.C. and Perona, M., 2002, Workload control in job shops: an introduction to the special issue, Production Planning \& Control, 2002, 13, 7, 565-567.

Herer Y. T. and Masin M., 1997, Mathematical programming formulation of CONWIP based production lines; and relationships to MRP, International Journal of Production Research, 35, 4, 1067-1076.

Hopp, W.J. and Spearman M.L., 1991, Throughput of a constant working process manufacturing line subject to fails, International Journal of Production Research, 29, 3, 635- 655 . 
Hopp, W.J. and Spearman M.L., 2001, Factory Physics: Foundations of Manufacturing Management, Irwin/McGraw-Hill.

Hübl, A., Altendorfer, K., Jodlbauer, H., Gansterer, M., Hartl, R.F., 2011, Flexible model for analyzing production systems with discrete event simulation, In Proceedings of the Winter Simulation Conference (WSC '11), S. Jain, R. Creasey, J. Himmelspach, K. P. White, and M. C. Fu (Eds.). Winter Simulation Conference 1559-1570.

Jacobs, F.R., and Bragg, D.J., 1988, Repetitive Lots: Flow-time Reductions Through Sequencing and Dynamic Batch Sizing, Decision Sciences, 19, 281-294.

Jaegler, Y., Jaegler, A., Burlat, P., Lamouri, S., \& Trentesaux, D., 2018, The ConWip production control system: a systematic review and classification, International Journal of Production Research, 56, 17, 5736-5757.

Jeong, H., Park, J., and Leachman, R.C., 1999, A Batch Splitting Method for a Job Shop Scheduling Problem in an MRP Environment, International Journal of Production Research, 37, 15, 3583-3598.

Jodlbauer, H. and Huber, A., 2008, Service-level performance of MRP, kanban, CONWIP and DBR due to parameter stability and environmental robustness, International Journal of Production Research, 46, 8, 2179-2195.

Kanet, J.J., 1988, Load-limited order release in job shop scheduling systems, Journal of Operations Management, 7, 3, 44 - 58.

Karmarkar, U.S., Kekre, S., Kekre, S., and S. Freeman, 1985, Lot-sizing and Lead-time Performance in a Manufacturing Cell, Interfaces, 15, 2, 1-9.

Kher, H.V., Malhorta., M.K., and Steele, D.S., 2000, The effect of push and pull lot splitting approaches on lot traceability and material handling costs in stochastic flow shop environments, International Journal of Production Research, 38, 1, 141-160.

Kropp, D.H., and Smunt, T.L., 1990, Optimal and Heuristic Models for Lot Splitting in a Flow Shop, Decision Sciences, 21, 4, 691-709.

Lalitha, J.L., Mohan, N., and Pillai V.M., 2017, Lot streaming in [N-1](1)+N(m) hybrid flow shop, Journal of Manufacturing Systems, 44, 12-21.

Land, M., Stevenson, M. and Thürer, M., 2014, Integrating load-based order release and priority dispatching, International Journal of Production Research, 52, 4, 1059-1073.

Land, M.J., 2006, Parameters and Sensitivity in Workload Control, International Journal of Production Economics, 104, 2, 625-638. 
Land, M.J., and Gaalman, G.J.C., 1998, The performance of workload control concepts in job shops: Improving the release method, International Journal of Production Economics, 56 $57,347-364$.

Land, M.J., Stevenson, M., Thürer, M., Gaalman, G.J.C., 2015, Job shop control: In search of the key to delivery improvements, International Journal of Production Economics, 168, 1, $257-266$.

Leonardo, D.G., Sereno, B., Silva, D., Sampaio, M., Massote A. and Simões, J., 2017, Implementation of hybrid Kanban-CONWIP system: A case study, Journal of Manufacturing Technology Management 28(6) 714-736.

Litchfield, J. and Narasimhan, R., 2000, Improving job shop performance throughout process queue management under transfer batching, Production and Operations Management, 9, 4, 336-348.

Lockwood, W. T., Mahmoodi, F., Ruben, R.A., and Mosier, C.T. 2000, Scheduling Unbalanced Cellular Manufacturing Systems with Lot Splitting, International Journal of Production Research, 38,4, 951-965.

Melnyk, S.A., and Ragatz, G.L., 1989, Order review/release: research issues and perspectives, International Journal of Production Research, 27, 7, 1081-1096.

Olaitan, O., Alfnes, E., Vatn, J. and Strandhagen, J.O., 2019, CONWIP implementation in a system with cross-trained teams, International Journal of Production Research, Online.

Prakash, J. and Chin, J.F., 2014, Implementation of hybrid parallel kanban-CONWIP system: A case study, Cogent Engineering 1, 1, 1-15.

Russell, G.R., and Fry, T.D., 1997, Order Review/Release and Lot Splitting in Drum-bufferrope, International Journal of Production Research, 35, 3, 827-845.

Slomp, J.J., Bokhorst, A.C., and Germs, R., 2009, A Lean Production Control System for HighVariety/Low-Volume Environments: A Case Study Implementation, Production Planning \& Control, 20, 7, 586-595.

Smunt, T.L., Buss, A.H., and Kropp, D.H., 1996, Lot Splitting in Stochastic Flow Shop and Job Shop Environments, Decision Sciences, 27, 2, 215-238.

Spearman, M.L., Woodruff, D.L., and Hopp, W.J., 1990, CONWIP: a pull alternative to kanban, International Journal of Production Research, 28, 5, 879-894.

Thürer, M., Fernandes, N.O., Ziengs, N., Stevenson, M., and Qu, T., 2019; On the Meaning of ConWIP Cards: An Assessment by Simulation, Journal of Industrial and Production Engineering, Forthcoming. 
Thürer, M., Fernandes, N.O., Carmo-Silva, S., and Stevenson, M., 2018, Lot Splitting under Load-limiting Order Release in High-Variety Shops: An Assessment by Simulation, Journal of Manufacturing Systems, 48, 63-72.

Thürer, M., Fernandes, N.O., Stevenson, M., and Qu, T., 2017, On the Backlog-sequencing Decision for Extending the Applicability of ConWIP to High-Variety Contexts: An Assessment by Simulation, International Journal of Production Research, 55, 16, 46954711.

Wagner, B. J., and Ragatz, G. L., 1994, The Impact of Lot Splitting on Due Date Performance, Journal of Operations Management, 12, 1, 13-25.

Zäpfel, G. and Missbauer, H., 1993, New concepts for production planning and control, European Journal of Operational Research, 67, 297 - 320.

Ziengs, N., Riezebos, J. and Germs, R., 2012, Placement of effective work-in-progress limits in route-specific unit-based pull systems, International Journal of Production Research, 50, $16,4358-4371$. 
Release Policy (RP) at Job Release

Transfer Policy (TP) on the Shop Floor

Number of ConWIP Cards

WIP Measure

Set-up Factor (Environmental Factor)

Number of lots (Environmental Factor)
- Release Policy 1 (synchronization): all lots of a job must be released together;

- Release Policy 2 (synchronization plus starvation avoidance): as for Policy 1, but a job may be released if the first station in the routing is starving; and,

- Release Policy 3 (no synchronization plus starvation avoidance): each lot that makes up a job can be released independently.

- Transfer Policy 1 (synchronization): each lot of a job must wait until all lots of the job are completed at each station in its routing before proceeding to the next station and finally to the customer;

- Transfer Policy 2 (synchronization plus starvation avoidance): as for Policy 1, but a lot may proceed to the next station even if not all lots of the job are completed if the next station is starving; and,

- Transfer Policy 3 (no synchronization): each lot that makes up a job can proceed independently through the shop floor, but each lot must wait until all lots of the job are completed before being delivered to the customer.

$30,36,42,48,54$ times the number of lots per job, and an infinite number of cards

- Number of Lots: the number of lots in the system; and,

- Workload: the total workload in the system.

- Zero; and

- $\quad$ Five percent of the operation time

2,3 and 4 
Table 2: Paired t-test Comparison of Means for the Percentage Tardy at a 0.05 Level.

\begin{tabular}{|c|c|c|c|c|c|c|c|}
\hline \multirow{2}{*}{$\begin{array}{l}\text { Number } \\
\text { of Lots }\end{array}$} & \multirow[b]{2}{*}{ Control Policies } & \multicolumn{2}{|c|}{ Total Throughput Time } & \multicolumn{2}{|c|}{ Percent Tardy } & \multicolumn{2}{|c|}{ Tardiness } \\
\hline & & $\begin{array}{l}\text { Estimated } \\
\text { mean } \\
\text { difference }\end{array}$ & $\begin{array}{l}0.95 \mathrm{Cl} \\
\text { half-with }\end{array}$ & $\begin{array}{l}\text { Estimated } \\
\text { mean } \\
\text { difference }\end{array}$ & $\begin{array}{l}0.95 \mathrm{Cl} \\
\text { half-with }\end{array}$ & $\begin{array}{l}\text { Estimated } \\
\text { mean } \\
\text { difference }\end{array}$ & $\begin{array}{l}0.95 \mathrm{Cl} \\
\text { half-with }\end{array}$ \\
\hline 2 & TP1RP2 - TP1RP1 & -1.550 & 0.152 & $-0,745$ & 0.0928 & -1.07 & 0.129 \\
\hline 3 & TP1RP2 - TP1RP1 & -0.365 & 0.0382 & -0.239 & 0.0519 & -0.204 & 0.0229 \\
\hline 4 & TP1RP2 - TP1RP1 & -0.395 & 0.0419 & -0.265 & 0.0453 & -0.237 & 0.0274 \\
\hline 2 & TP2RP2 - TP2RP1 & -1.41 & 0.146 & -0.658 & 0.0915 & -0.965 & 0.122 \\
\hline 3 & TP2RP2 - TP2RP1 & -0.281 & 0.0380 & $-0,112$ & 0,0532 & -0.166 & 0.0241 \\
\hline 4 & TP2RP2 - TP2RP1 & -0.266 & 0.0413 & -0.142 & 0.0558 & -0.161 & 0.0242 \\
\hline 2 & TP3RP2 - TP3RP1 & -1.02 & 0.108 & -0.517 & 0.0699 & -0.648 & 0.0836 \\
\hline 3 & TP3RP2 - TP3RP1 & -0.185 & 0.0304 & -0.109 & 0.0435 & -0.0884 & 0.0163 \\
\hline 4 & TP3RP2 - TP3RP1 & -0.182 & 0.0315 & -0.137 & 0.0382 & -0.0923 & 0.0176 \\
\hline 2 & TP3RP1 - TP1RP1 & -1.800 & 0.0956 & -1.440 & 0.0856 & -0.738 & 0.0821 \\
\hline 3 & TP3RP1 - TP1RP1 & -1.630 & 0.0364 & -1.460 & 0.0554 & -0.402 & 0.0256 \\
\hline 4 & TP3RP1 - TP1RP1 & -1.830 & 0.0418 & -1.48 & 0.0611 & -0.482 & 0.0314 \\
\hline 2 & TP3RP1 - TP2RP1 & -1.350 & 0.0780 & -1.12 & 0.0759 & -0.559 & 0.0639 \\
\hline 3 & TP3RP1 - TP2RP1 & -1.240 & 0.0363 & -1.10 & 0.0581 & -0.302 & 0.0243 \\
\hline 4 & TP3RP1 - TP2RP1 & -1.330 & 0.0324 & -1.08 & 0.0540 & --0335 & 0.0210 \\
\hline 2 & TP3RP2 - TP1RP2 & -1.270 & 0.0612 & -1.210 & 0.0662 & -0.362 & 0.0414 \\
\hline 3 & TP3RP2 - TP1RP2 & -1.450 & 0.0303 & -1.330 & 0.0624 & -0.287 & 0.0194 \\
\hline 4 & TP3RP2 - TP1RP2 & -1.610 & 0.0372 & -1.350 & 0.0600 & -0.337 & 0.0228 \\
\hline 2 & TP3RP2 - TP2RP2 & -0.962 & 0.0559 & -0.983 & 0.0672 & -0.242 & 0.0338 \\
\hline 3 & TP3RP2 - TP2RP2 & -1.140 & 0.0316 & -1.100 & 0.0555 & -0.224 & 0.0176 \\
\hline 4 & TP3RP2 - TP2RP2 & -1.250 & 0.0361 & -1.080 & 0.0550 & -0.267 & 0.0194 \\
\hline
\end{tabular}


Table 3: Utilization Results for a Set-up Factor of Five Percent of the Operation Time.

\begin{tabular}{lcccc}
\hline & $\begin{array}{c}\text { Number } \\
\text { of Lots }\end{array}$ & $\begin{array}{c}\text { Release } \\
\text { Policy 1 }\end{array}$ & $\begin{array}{l}\text { Release } \\
\text { Policy 2 }\end{array}$ & $\begin{array}{l}\text { Release } \\
\text { Policy 3 }\end{array}$ \\
\hline Transfer & 2 & $86.97 \%$ & $86.97 \%$ & $86.99 \%$ \\
Policy 1 & 3 & $86.23 \%$ & $86.23 \%$ & $86.24 \%$ \\
& 4 & $85.86 \%$ & $85.86 \%$ & $85.87 \%$ \\
\hline \multirow{2}{*}{ Transfer } & 2 & $86.98 \%$ & $86.98 \%$ & $87.00 \%$ \\
Policy 2 & 3 & $86.24 \%$ & $86.24 \%$ & $86.26 \%$ \\
& 4 & $85.87 \%$ & $85.87 \%$ & $85.89 \%$ \\
\hline \multirow{2}{*}{ Transfer } & 2 & $87.12 \%$ & $87.12 \%$ & $87.15 \%$ \\
Policy 3 & 3 & $86.38 \%$ & $86.38 \%$ & $86.40 \%$ \\
& 4 & $85.99 \%$ & $85.99 \%$ & $86.01 \%$ \\
\hline
\end{tabular}



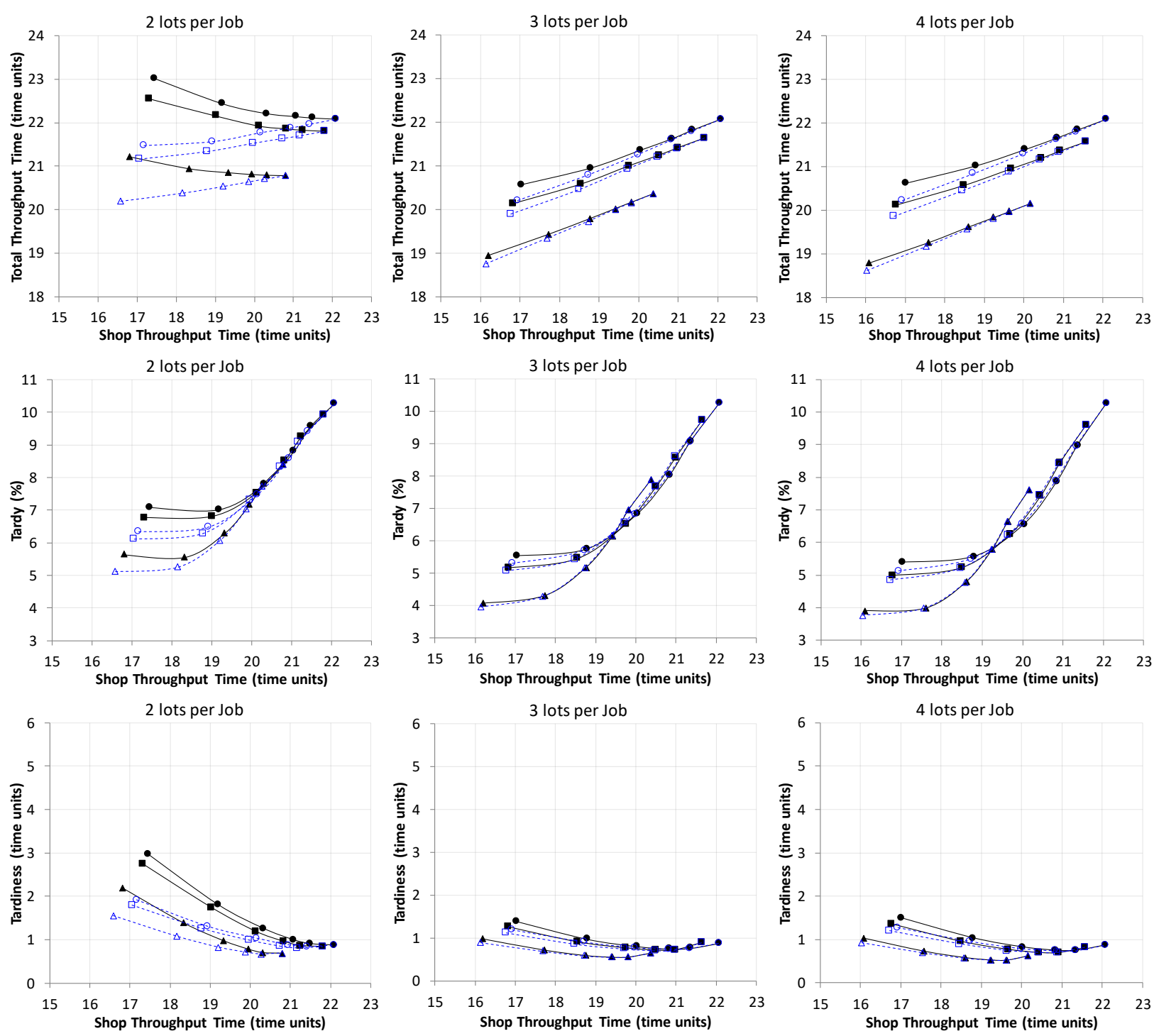

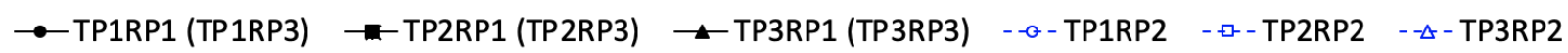

Figure 1: Results for the Transfer (TP) and Release (RP) Policies when Controlling the Number of Lots. 

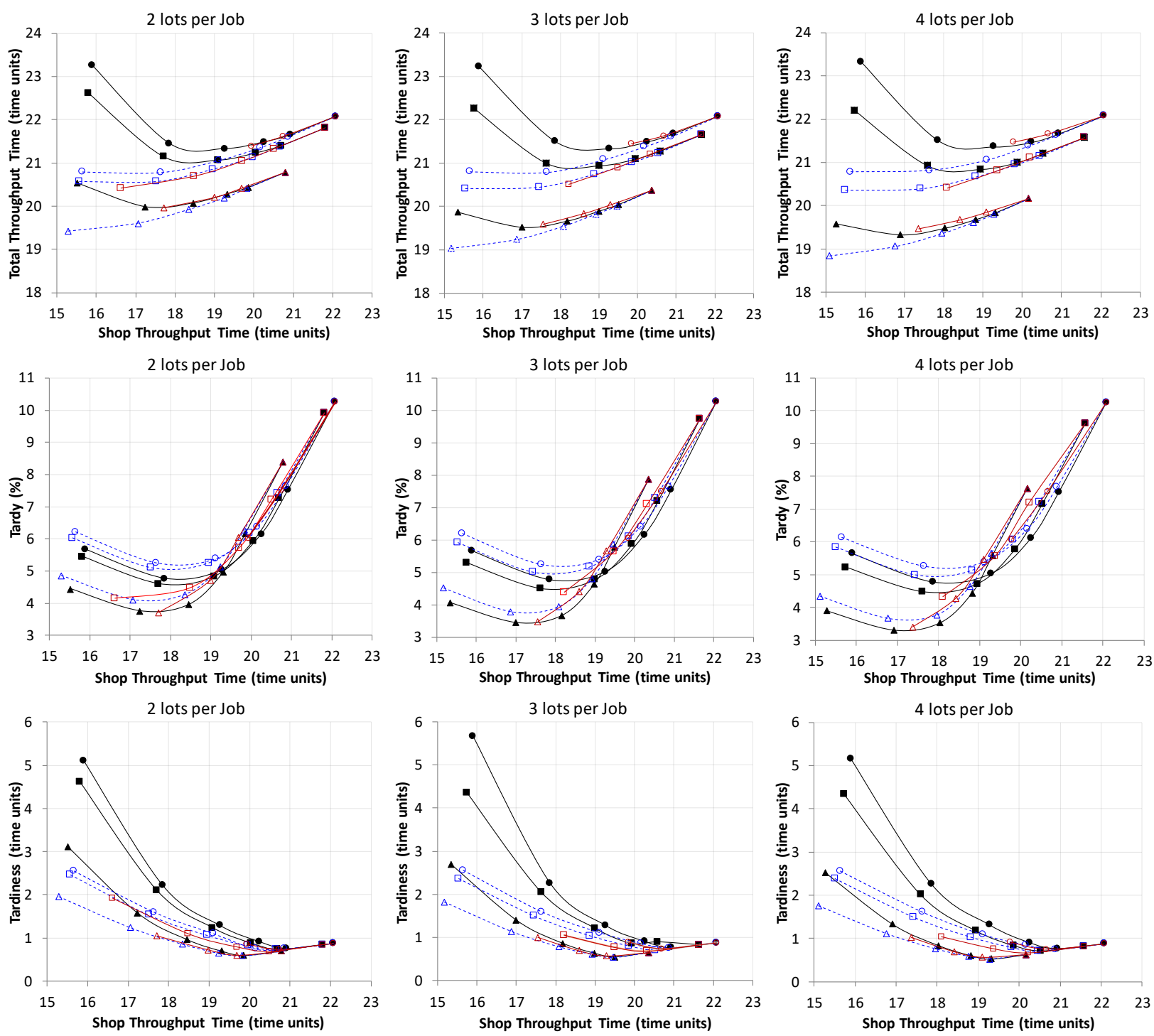

$\bullet$ TP1RP1 ๘-TP2RP1 $\leftarrow$ TP3RP1

--๑- TP1RP2 - - - - TP2RP2 -- - TP3RP2

$\triangle$ TP3RP3 - -TP2RP3 - TP1RP3

Figure 2: Results for the Transfer (TP) and Release (RP) Policies when Controlling the Shop Load. 

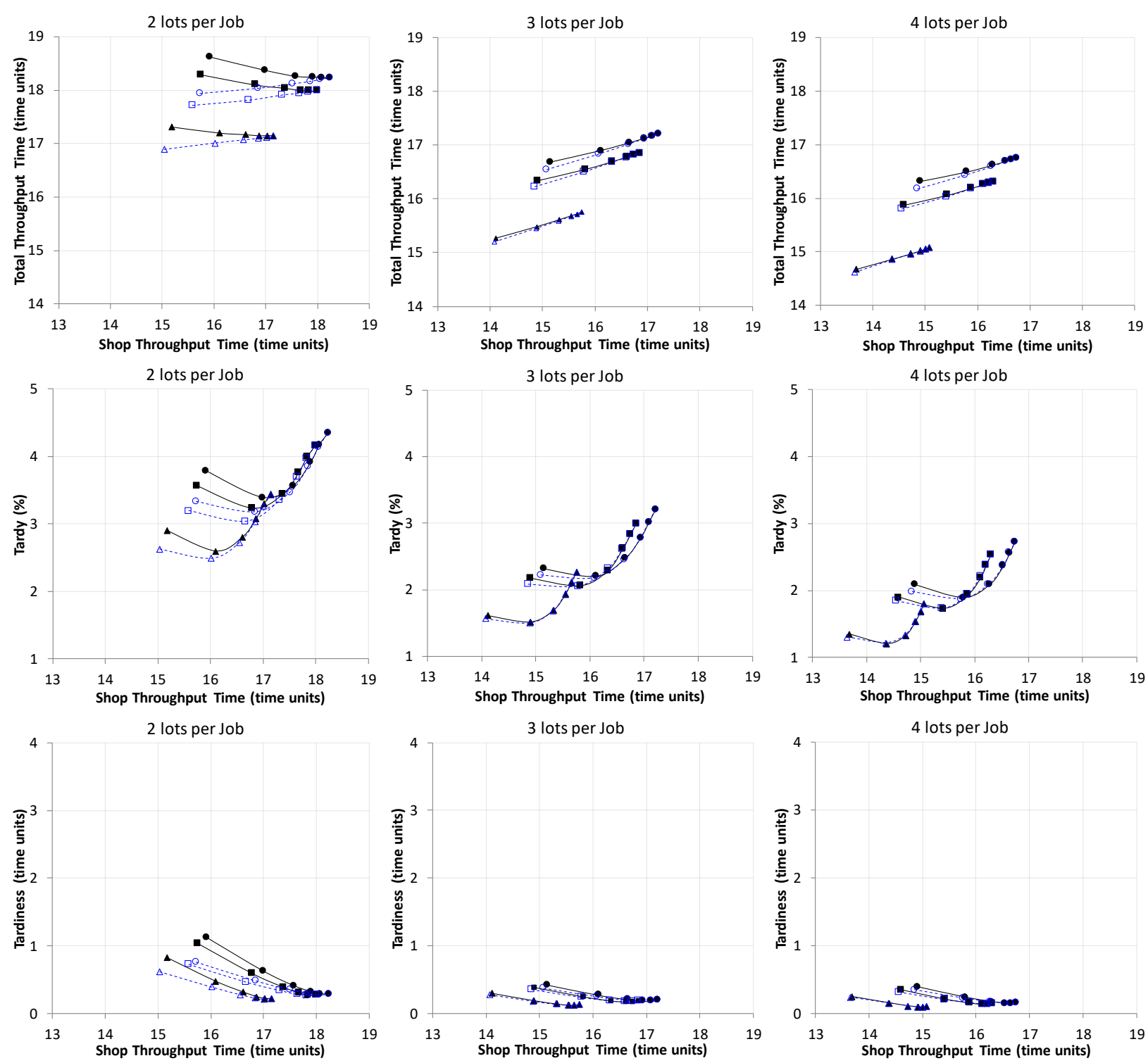

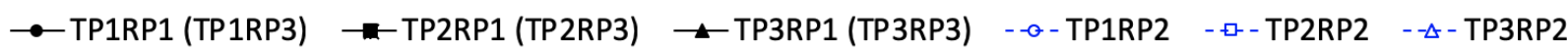

Figure 3: Results for the Transfer (TP) and Release (RP) Policies with a Setup Factor of 5\% when Controlling the Number of Lots. 

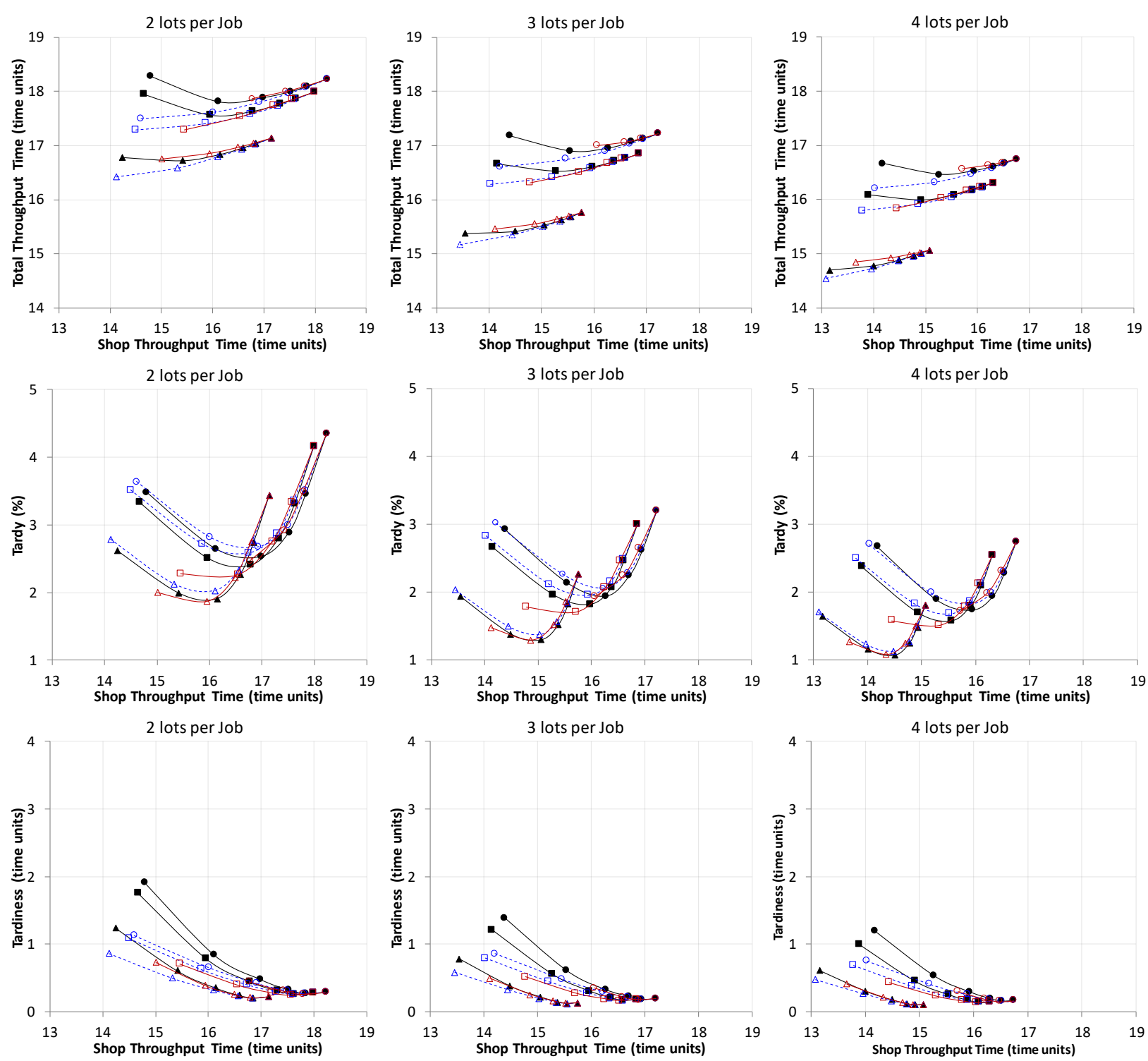

$\bullet$ TP1RP1 - TP2RP1 $\leftarrow$ TP3RP1

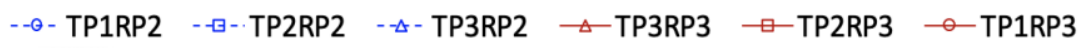

Figure 4: Results for the Transfer (TP) and Release (RP) Policies with a Setup Factor of $5 \%$ when Controlling the Shop Load 


\section{Appendix A}

Table A1: Results for the Transfer Policies (TP) and Release Policies (RP) when Controlling the Number of Lots - 2 Lots per Job.

\begin{tabular}{|c|c|c|c|c|c|c|c|}
\hline Performance measure & Policy & Limit $1^{\ddagger}$ & Limit 2 & Limit 3 & Limit 4 & Limit 5 & No Limit \\
\hline \multirow{6}{*}{$\begin{array}{c}\text { Shop Throughput Time } \\
\text { (time units) }\end{array}$} & TP1RP1* & 17.447 & 19.182 & 20.319 & 21.061 & 21.489 & 22.084 \\
\hline & TP2RP1** & 17.317 & 19.016 & 20.124 & 20.825 & 21.240 & 21.808 \\
\hline & TP3RP1*** & 16.804 & 18.326 & 19.328 & 19.939 & 20.307 & 20.789 \\
\hline & TP1RP2 & 17.169 & 18.928 & 20.152 & 20.939 & 21.416 & 22.084 \\
\hline & TP2RP2 & 17.051 & 18.782 & 19.969 & 20.723 & 21.169 & 21.808 \\
\hline & TP3RP2 & 16.576 & 18.150 & 19.197 & 19.860 & 20.261 & 20.789 \\
\hline \multirow{6}{*}{$\begin{array}{c}\text { Total Throughput Time } \\
\text { (time units) }\end{array}$} & TP1RP1* & 23.018 & 22.438 & 22.211 & 22.143 & 22.111 & 22.084 \\
\hline & TP2RP1 ** & 22.571 & 22.160 & 21.296 & 21.863 & 21.830 & 21.808 \\
\hline & TP3RP $1^{* * *}$ & 21.221 & 20.947 & 20.856 & 20.815 & 20.798 & 20.789 \\
\hline & TP1RP2 & 21.471 & 21.526 & 21.769 & 21.882 & 21.966 & 22.084 \\
\hline & TP2RP2 & 21.159 & 21.334 & 21.527 & 21.638 & 21.701 & 21.808 \\
\hline & TP3RP2 & 20.197 & 20.383 & 20.538 & 20.647 & 20.708 & 20.789 \\
\hline \multirow{6}{*}{$\begin{array}{l}\text { Tardy } \\
(\%)\end{array}$} & TP1RP1* & 7.076 & 7.009 & 7.791 & 7.798 & 9.576 & 10.269 \\
\hline & TP2RP1** & 6.772 & 6.801 & 7.526 & 8.517 & 9.234 & 9.907 \\
\hline & TP3RP1*** & 5.636 & 5.560 & 6.303 & 7.165 & 7.819 & 8.397 \\
\hline & TP1RP2 & 6.331 & 6.479 & 7.476 & 8.566 & 9.409 & 10.269 \\
\hline & TP2RP2 & 6.102 & 6.279 & 7.316 & 8.322 & 9.080 & 9.907 \\
\hline & TP3RP2 & 5.119 & 5.256 & 6.070 & 7.025 & 7.718 & 8.397 \\
\hline \multirow{6}{*}{$\begin{array}{l}\text { Tardiness } \\
\text { (time units) }\end{array}$} & TP1RP1* & 2.982 & 1.82 & 1.265 & 1.003 & 0.909 & 0.875 \\
\hline & TP2RP1** & 2.758 & 1.751 & 1.198 & 0.965 & 0.868 & 0.841 \\
\hline & TP3RP $1^{* * *}$ & 2.198 & 1.395 & 0.985 & 0.793 & 0.710 & 0.696 \\
\hline & TP1RP2 & 1.913 & 1.311 & 1.037 & 0.884 & 0.845 & 0.875 \\
\hline & TP2RP2 & 1.793 & 1.265 & 0.995 & 0.860 & 0.816 & 0.841 \\
\hline & TP3RP2 & 1.551 & 1.083 & 0.831 & 0.719 & 0.674 & 0.696 \\
\hline
\end{tabular}

*Equivalent to TP1RP3; ** Equivalent to TP2RP3; *** Equivalent to TP3RP3; ${ }^{\ddagger}$ Tightest limit level on shop WIP 
Table A2: Results for the Transfer Policies (TP) and Release Policies (RP) when Controlling the Number of Lots -3 Lots per Job.

\begin{tabular}{|c|c|c|c|c|c|c|c|}
\hline Performance measure & Policy & Limit $1^{\ddagger}$ & Limit 2 & Limit 3 & Limit 4 & Limit 5 & No Limit \\
\hline \multirow{6}{*}{$\begin{array}{c}\text { Shop Throughput Time } \\
\text { (time units) }\end{array}$} & TP1RP1* & 17.031 & 18.791 & 20.038 & 20.842 & 21.362 & 22.084 \\
\hline & TP2RP1** & 16.831 & 18.546 & 19.750 & 20.509 & 20.988 & 21.651 \\
\hline & TP3RP1*** & 16.200 & 17.727 & 18.759 & 19.418 & 19.816 & 20.368 \\
\hline & TP1RP2 & 16.931 & 18.732 & 19.987 & 20.825 & 21.342 & 22.084 \\
\hline & TP2RP2 & 16.772 & 18.486 & 19.710 & 20.480 & 20.969 & 21.651 \\
\hline & TP3RP2 & 16.135 & 17.685 & 18.722 & 19.405 & 19.804 & 20.368 \\
\hline \multirow{6}{*}{$\begin{array}{c}\text { Total Throughput Time } \\
\text { (time units) }\end{array}$} & TP1RP1* & 20.580 & 20.962 & 21.368 & 21.633 & 21.832 & 22.084 \\
\hline & TP2RP1** & 20.140 & 20.591 & 21.011 & 21.257 & 21.430 & 21.651 \\
\hline & TP3RP1*** & 18.953 & 19.439 & 19.795 & 20.031 & 20.172 & 20.368 \\
\hline & TP1RP2 & 20.214 & 20.808 & 21.275 & 21.604 & 21.802 & 22.084 \\
\hline & TP2RP2 & 19.910 & 20.467 & 20.947 & 21.220 & 21.401 & 21.651 \\
\hline & TP3RP2 & 18.768 & 19.354 & 19.739 & 20.014 & 20.157 & 20.368 \\
\hline \multirow{6}{*}{$\begin{array}{l}\text { Tardy } \\
(\%)\end{array}$} & TP1RP1* & 5.538 & 5.754 & 6.839 & 8.033 & 9.078 & 10.269 \\
\hline & TP2RP1 ** & 5.178 & 5.462 & 6.530 & 7.682 & 8.572 & 9.727 \\
\hline & TP3RP $1^{* * *}$ & 4.078 & 4.310 & 5.179 & 6.153 & 6.961 & 7.883 \\
\hline & TP1RP2 & 5.299 & 5.715 & 6.821 & 8.063 & 9.050 & 10.269 \\
\hline & TP2RP2 & 5.066 & 5.431 & 6.569 & 7.682 & 8.601 & 9.727 \\
\hline & TP3RP2 & 3.969 & 4.293 & 5.173 & 6.175 & 6.959 & 7.883 \\
\hline \multirow{6}{*}{$\begin{array}{l}\text { Tardiness } \\
\text { (time units) }\end{array}$} & TP1RP1* & 1.382 & 0.971 & 0.802 & 0.744 & 0.759 & 0.875 \\
\hline & TP2RP1** & 1.260 & 0.906 & 0.762 & 0.709 & 0.717 & 0.892 \\
\hline & TP3RP1*** & 0.980 & 0.721 & 0.594 & 0.555 & 0.559 & 0.650 \\
\hline & TP1RP2 & 1.179 & 0.898 & 0.770 & 0.737 & 0.752 & 0.875 \\
\hline & TP2RP2 & 1.116 & 0.853 & 0.742 & 0.703 & 0.712 & 0.892 \\
\hline & TP3RP2 & 0.892 & 0.689 & 0.583 & 0.553 & 0.560 & 0.650 \\
\hline
\end{tabular}

*Equivalent to TP1RP3; ** Equivalent to TP2RP3; *** Equivalent to TP3RP3; ${ }^{\ddagger}$ Tightest limit level on shop WIP 
Table A3: Results for the Transfer Policies (TP) and Release Policies (RP) when Controlling the Number of Lots -4 Lots per Job.

\begin{tabular}{|c|c|c|c|c|c|c|c|}
\hline Performance measure & Policy & Limit $1^{\ddagger}$ & Limit 2 & Limit 3 & Limit 4 & Limit 5 & No Limit \\
\hline \multirow{6}{*}{$\begin{array}{c}\text { Shop Throughput Time } \\
\text { (time units) }\end{array}$} & TP1RP1* & 17.021 & 18.801 & 20.041 & 20.852 & 21.364 & 22.084 \\
\hline & TP2RP1** & 16.881 & 18.498 & 19.687 & 20.447 & 20.930 & 21.577 \\
\hline & TP3RP1*** & 16.086 & 17.592 & 18.610 & 19.242 & 19.632 & 20.160 \\
\hline & TP1RP2 & 16.924 & 18.729 & 19.988 & 20.828 & 21.335 & 22.084 \\
\hline & TP2RP2 & 16.722 & 18.455 & 19.644 & 20.421 & 20.900 & 21.577 \\
\hline & TP3RP2 & 16.030 & 17.544 & 18.574 & 19.226 & 19.626 & 20.160 \\
\hline \multirow{6}{*}{$\begin{array}{c}\text { Total Throughput Time } \\
\text { (time units) }\end{array}$} & TP1RP1* & 20.628 & 21.026 & 21.397 & 21.662 & 21.841 & 22.084 \\
\hline & TP2RP1** & 20.115 & 20.570 & 20.955 & 21.197 & 21.370 & 21.577 \\
\hline & TP3RP1*** & 18.802 & 19.268 & 19.627 & 19.841 & 19.977 & 20.160 \\
\hline & TP1RP2 & 20.234 & 20.846 & 21.301 & 21.624 & 21.799 & 22.084 \\
\hline & TP2RP2 & 19.866 & 20.454 & 20.874 & 21.162 & 21.329 & 21.577 \\
\hline & TP3RP2 & 18.620 & 19.180 & 19.571 & 19.818 & 19.967 & 20.160 \\
\hline \multirow{6}{*}{$\begin{array}{l}\text { Tardy } \\
(\%)\end{array}$} & TP1RP1* & 5.400 & 5.583 & 6.575 & 7.874 & 8.978 & 10.269 \\
\hline & TP2RP1 ** & 5.001 & 2.239 & 6.255 & 7.431 & 8.453 & 9.615 \\
\hline & TP3RP $1^{* * *}$ & 3.919 & 3.996 & 4.813 & 5.793 & 6.648 & 7.635 \\
\hline & TP1RP2 & 5.136 & 5.511 & 6.581 & 7.910 & 8.963 & 10.269 \\
\hline & TP2RP2 & 4.859 & 5.216 & 6.232 & 7.468 & 8.439 & 9.615 \\
\hline & TP3RP2 & 3.782 & 3.995 & 4.788 & 5.802 & 6.652 & 7.635 \\
\hline \multirow{6}{*}{$\begin{array}{l}\text { Tardiness } \\
\text { (time units) }\end{array}$} & TP1RP1* & 1.505 & 1.040 & 0.827 & 0.752 & 0.752 & 0.875 \\
\hline & TP2RP1** & 1.364 & 0.961 & 0.773 & 0.702 & 0.703 & 0.817 \\
\hline & TP3RP1*** & 1.023 & 0.729 & 0.586 & 0.534 & 0.531 & 0.625 \\
\hline & TP1RP2 & 1.268 & 0.956 & 0.794 & 0.746 & 0.746 & 0.875 \\
\hline & TP2RP2 & 1.197 & 0.898 & 0.743 & 0.698 & 0.697 & 0.817 \\
\hline & TP3RP2 & 0.931 & 0.699 & 0.576 & 0.531 & 0.531 & 0.625 \\
\hline
\end{tabular}

\footnotetext{
${ }^{*}$ Equivalent to TP1RP3; ** Equivalent to TP2RP3; *** Equivalent to TP3RP3; ${ }^{\ddagger}$ Tightest limit level on shop WIP
} 
Table A4: Results for the Transfer Policies (TP) and Release Policies (RP) when Controlling the Shop Load-2 Lots per Job.

\begin{tabular}{|c|c|c|c|c|c|c|c|}
\hline Performance measure & Policy & Limit $1^{\ddagger}$ & Limit 2 & Limit 3 & Limit 4 & Limit 5 & No Limit \\
\hline \multirow{9}{*}{$\begin{array}{c}\text { Shop Throughput Time } \\
\text { (time units) }\end{array}$} & TP1RP1 & 15.900 & 17.858 & 19.272 & 20.256 & 20.920 & 22.084 \\
\hline & TP2RP1 & 15.811 & 17.709 & 19.087 & 20.052 & 20.698 & 21.808 \\
\hline & TP3RP1 & 15.509 & 17.233 & 18.456 & 19.315 & 19.857 & 20.789 \\
\hline & TP1RP2 & 15.656 & 17.643 & 19.117 & 20.160 & 20.871 & 22.084 \\
\hline & TP2RP2 & 15.571 & 17.523 & 18.965 & 19.965 & 20.663 & 21.808 \\
\hline & TP3RP2 & 15.295 & 17.071 & 18.353 & 19.239 & 19.827 & 20.789 \\
\hline & TP1RP3 & & & & 19.928 & 20.743 & 22.084 \\
\hline & TP2RP3 & & & 18.485 & 19.699 & 20.501 & 21.808 \\
\hline & TP3RP2 & & & 17.711 & 18.989 & 19.692 & 20.789 \\
\hline \multirow{9}{*}{$\begin{array}{c}\text { Total Throughput Time } \\
\text { (time units) }\end{array}$} & TP1RP1 & 23.263 & 21.452 & 21.333 & 21.487 & 21.650 & 22.084 \\
\hline & TP2RP1 & 22.617 & 21.144 & 21.060 & 21.231 & 21.401 & 21.808 \\
\hline & TP3RP1 & 20.539 & 19.982 & 20.070 & 20.282 & 20.438 & 20.789 \\
\hline & TP1RP2 & 20.798 & 20.783 & 21.063 & 21.357 & 21.607 & 22.084 \\
\hline & TP2RP2 & 20.570 & 20.568 & 20.852 & 21.127 & 21.376 & 21.808 \\
\hline & TP3RP2 & 19.416 & 19.602 & 19.922 & 20.186 & 20.413 & 20.789 \\
\hline & TP1RP3 & & & & 21.396 & 21.621 & 22.084 \\
\hline & TP2RP3 & & & 20.699 & 21.042 & 21.323 & 21.808 \\
\hline & TP3RP3 & & & 19.965 & 20.201 & 20.420 & 20.789 \\
\hline \multirow{9}{*}{$\begin{array}{c}\text { Tardy } \\
(\%)\end{array}$} & TP1RP1 & 5.671 & 4.768 & 5.035 & 6.148 & 7.256 & 10.269 \\
\hline & TP2RP1 & 5.445 & 4.597 & 4.830 & 5.944 & 7.272 & 9.907 \\
\hline & TP3RP1 & 4.445 & 3.755 & 3.955 & 4.975 & 6.174 & 8.397 \\
\hline & TP1RP2 & 6.221 & 5.261 & 5.385 & 6.381 & 7.643 & 10.269 \\
\hline & TP2RP2 & 6.031 & 5.108 & 5.266 & 6.183 & 7.427 & 9.907 \\
\hline & TP3RP2 & 4.863 & 4.111 & 4.268 & 5.129 & 6.288 & 8.397 \\
\hline & TP1RP3 & & & & 6.032 & 7.517 & 10.269 \\
\hline & TP2RP3 & & & 4.476 & 5.716 & 7.217 & 9.907 \\
\hline & TP3RP3 & & & 3.712 & 4.713 & 6.056 & 8.397 \\
\hline \multirow{9}{*}{$\begin{array}{l}\text { Tardiness } \\
\text { (time units) }\end{array}$} & TP1RP1 & 5.103 & 2.212 & 1.290 & 0.914 & 0.758 & 0.875 \\
\hline & TP2RP1 & 4.606 & 2.094 & 1.231 & 0.872 & 0.732 & 0.841 \\
\hline & TP3RP1 & 3.100 & 1.571 & 0.961 & 0.693 & 0.595 & 0.696 \\
\hline & TP1RP2 & 2.546 & 1.593 & 1.097 & 0.743 & 0.749 & 0.875 \\
\hline & TP2RP2 & 2.467 & 1.529 & 1.062 & 0.818 & 0.728 & 0.841 \\
\hline & TP3RP2 & 1.960 & 1.237 & 0.858 & 0.650 & 0.591 & 0.696 \\
\hline & TP1RP3 & & & & 0.862 & 0.728 & 0.875 \\
\hline & TP2RP3 & & & 1.095 & 0.785 & 0.684 & 0.841 \\
\hline & TP3RP3 & & & 1.044 & 0.723 & 0.602 & 0.696 \\
\hline
\end{tabular}


Table A5: Results for the Transfer Policies (TP) and Release Policies (RP) when Controlling the Shop Load - 3 Lots per Job.

\begin{tabular}{|c|c|c|c|c|c|c|c|}
\hline Performance measure & Policy & Limit $1^{\ddagger}$ & Limit 2 & Limit 3 & Limit 4 & Limit 5 & No Limit \\
\hline \multirow{9}{*}{$\begin{array}{c}\text { Shop Throughput Time } \\
\text { (time units) }\end{array}$} & TP1RP1 & 15.902 & 17.859 & 19.267 & 20.256 & 20.937 & 22.084 \\
\hline & TP2RP1 & 15.758 & 17.639 & 19.003 & 19.941 & 20.589 & 21.651 \\
\hline & TP3RP1 & 15.348 & 17.003 & 18.172 & 18.991 & 19.502 & 20.368 \\
\hline & TP1RP2 & 15.652 & 17.647 & 19.121 & 20.165 & 20.872 & 22.084 \\
\hline & TP2RP2 & 15.536 & 17.449 & 18.876 & 19.863 & 20.532 & 21.651 \\
\hline & TP3RP2 & 15.172 & 16.877 & 18.090 & 18.929 & 19.471 & 20.368 \\
\hline & TP1RP3 & & & & 19.838 & 20.682 & 22.084 \\
\hline & TP2RP3 & & & 18.225 & 19.493 & 20.330 & 21.651 \\
\hline & TP3RP2 & & & 17.555 & 18.603 & 19.291 & 20.368 \\
\hline \multirow{9}{*}{$\begin{array}{l}\text { Total Throughput Time } \\
\text { (time units) }\end{array}$} & TP1RP1 & 23.217 & 21.504 & 21.327 & 21.488 & 21.675 & 22.084 \\
\hline & TP2RP1 & 22.260 & 20.999 & 20.942 & 21.094 & 21.282 & 21.651 \\
\hline & TP3RP1 & 19.863 & 19.514 & 19.656 & 19.883 & 20.037 & 20.368 \\
\hline & TP1RP2 & 20.802 & 20.785 & 21.079 & 21.373 & 21.608 & 22.084 \\
\hline & TP2RP2 & 20.408 & 20.439 & 20.736 & 21.009 & 21.225 & 21.651 \\
\hline & TP3RP2 & 19.035 & 19.239 & 19.547 & 19.824 & 20.007 & 20.368 \\
\hline & TP1RP3 & & & & 21.444 & 21.630 & 22.084 \\
\hline & TP2RP3 & & & 20.505 & 20.899 & 21.198 & 21.651 \\
\hline & TP3RP3 & & & 19.598 & 19.838 & 20.036 & 20.368 \\
\hline \multirow{9}{*}{$\begin{array}{l}\text { Tardy } \\
(\%)\end{array}$} & TP1RP1 & 5.663 & 4.778 & 5.025 & 6.163 & 7.539 & 10.269 \\
\hline & TP2RP1 & 5.296 & 4.500 & 4.781 & 5.866 & 7.191 & 9.727 \\
\hline & TP3RP1 & 4.068 & 3.452 & 3.671 & 4.641 & 5.790 & 7.883 \\
\hline & TP1RP2 & 6.193 & 5.236 & 5.396 & 6.411 & 7.654 & 10.269 \\
\hline & TP2RP2 & 5.916 & 5.004 & 5.172 & 6.105 & 7.296 & 9.727 \\
\hline & TP3RP2 & 4.522 & 3.792 & 3.945 & 4.816 & 5.878 & 7.883 \\
\hline & TP1RP3 & & & 6.068 & 7.504 & 10.269 & 6.068 \\
\hline & TP2RP3 & & & 4.376 & 5.642 & 7.104 & 9.727 \\
\hline & TP3RP3 & & & 3.484 & 4.408 & 5.658 & 7.883 \\
\hline \multirow{9}{*}{$\begin{array}{l}\text { Tardiness } \\
\text { (time units) }\end{array}$} & TP1RP1 & 5.663 & 2.259 & 1.282 & 0.916 & 0.767 & 0.875 \\
\hline & TP2RP1 & 4.348 & 2.043 & 1.207 & 0.854 & 0.892 & 0.826 \\
\hline & TP3RP1 & 2.692 & 1.400 & 0.867 & 0.633 & 0.547 & 0.650 \\
\hline & TP1RP2 & 2.559 & 1.591 & 1.105 & 0.851 & 0.751 & 0.875 \\
\hline & TP2RP2 & 2.365 & 1.499 & 1.040 & 0.807 & 0.709 & 0.826 \\
\hline & TP3RP2 & 1.821 & 1.141 & 0.786 & 0.612 & 0.539 & 0.650 \\
\hline & TP1RP3 & & & & 0.897 & 0.733 & 0.875 \\
\hline & TP2RP3 & & & 1.050 & 0.769 & 0.678 & 0.826 \\
\hline & TP3RP3 & & & 1.003 & 0.695 & 0.575 & 0.650 \\
\hline
\end{tabular}


Table A6: Results for the Transfer Policies (TP) and Release Policies (RP) when Controlling the Shop Load-4 Lots per Job.

\begin{tabular}{|c|c|c|c|c|c|c|c|}
\hline Performance measure & Policy & Limit $1 \ddagger$ & Limit 2 & Limit 3 & Limit 4 & Limit 5 & No Limit \\
\hline \multirow{9}{*}{$\begin{array}{c}\text { Shop Throughput Time } \\
\text { (time units) }\end{array}$} & TP1RP1 & 15.904 & 17.864 & 19.278 & 20.252 & 20.929 & 22.084 \\
\hline & TP2RP1 & 15.734 & 17.603 & 18.941 & 19.873 & 20.529 & 21.577 \\
\hline & TP3RP1 & 15.279 & 16.903 & 18.037 & 18.821 & 19.319 & 20.160 \\
\hline & TP1RP2 & 15.647 & 17.648 & 19.110 & 20.167 & 20.883 & 22.084 \\
\hline & TP2RP2 & 15.505 & 17.419 & 18.828 & 19.813 & 20.458 & 21.577 \\
\hline & TP3RP2 & 15.108 & 16.770 & 17.953 & 18.761 & 19.283 & 20.160 \\
\hline & TP1RP3 & & & & 19.779 & 20.660 & 22.084 \\
\hline & TP2RP3 & & & 18.096 & 19.371 & 20.211 & 21.577 \\
\hline & TP3RP2 & & & 17.368 & 18.423 & 19.097 & 20.160 \\
\hline \multirow{9}{*}{$\begin{array}{c}\text { Total Throughput Time } \\
\text { (time units) }\end{array}$} & TP1RP1 & 23.318 & 21.509 & 21.366 & 21.472 & 21.663 & 22.084 \\
\hline & TP2RP1 & 22.208 & 20.923 & 20.846 & 21.004 & 21.214 & 21.577 \\
\hline & TP3RP1 & 19.578 & 19.325 & 19.478 & 19.678 & 19.834 & 20.160 \\
\hline & TP1RP2 & 20.780 & 20.813 & 21.051 & 21.377 & 21.621 & 22.084 \\
\hline & TP2RP2 & 20.357 & 20.392 & 20.669 & 20.943 & 21.145 & 21.577 \\
\hline & TP3RP2 & 18.845 & 19.059 & 19.355 & 19.614 & 19.799 & 20.160 \\
\hline & TP1RP3 & & & & 21.471 & 21.659 & 22.084 \\
\hline & TP2RP3 & & & 20.411 & 20.811 & 21.100 & 21.577 \\
\hline & TP3RP3 & & & 19.474 & 19.675 & 19.851 & 20.160 \\
\hline \multirow{9}{*}{$\begin{array}{c}\text { Tardy } \\
(\%)\end{array}$} & TP1RP1 & 5.654 & 4.787 & 5.046 & 6.131 & 7.537 & 10.269 \\
\hline & TP2RP1 & 5.232 & 4.481 & 4.715 & 5.788 & 7.156 & 9.615 \\
\hline & TP3RP1 & 3.911 & 3.322 & 3.543 & 4.456 & 5.605 & 7.635 \\
\hline & TP1RP2 & 6.144 & 5.266 & 5.394 & 6.407 & 7.685 & 10.269 \\
\hline & TP2RP2 & 5.839 & 4.994 & 5.133 & 6.073 & 7.217 & 9.615 \\
\hline & TP3RP2 & 4.357 & 3.678 & 3.785 & 4.650 & 5.659 & 7.635 \\
\hline & TP1RP3 & & & & 6.076 & 7.551 & 10.269 \\
\hline & TP2RP3 & & & 4.338 & 5.576 & 7.209 & 9.615 \\
\hline & TP3RP3 & & & 3.414 & 4.290 & 5.476 & 7.635 \\
\hline \multirow{9}{*}{$\begin{array}{l}\text { Tardiness } \\
\text { (time units) }\end{array}$} & TP1RP1 & 5.152 & 2.260 & 1.316 & 0.904 & 0.765 & 0.875 \\
\hline & TP2RP1 & 4.339 & 2.009 & 1.180 & 0.836 & 0.716 & 0.817 \\
\hline & TP3RP1 & 2.525 & 1.339 & 0.839 & 0.606 & 0.526 & 0.625 \\
\hline & TP1RP2 & 2.556 & 1.611 & 1.094 & 0.855 & 0.752 & 0.875 \\
\hline & TP2RP2 & 2.375 & 1.491 & 1.030 & 0.796 & 0.701 & 0.817 \\
\hline & TP3RP2 & 1.753 & 1.105 & 0.756 & 0.582 & 0.518 & 0.625 \\
\hline & TP1RP3 & & & & 0.926 & 0.751 & 0.875 \\
\hline & TP2RP3 & & & 1.043 & 0.766 & 0.672 & 0.817 \\
\hline & TP3RP3 & & & 1.028 & 0.691 & 0.563 & 0.625 \\
\hline
\end{tabular}

${ }^{\ddagger}$ Tightest limit level on shop WIP 
Table A7: Results for the Transfer Policies (TP) and Release Policies (RP) with a Setup Factor of 5\% when Controlling the Number of Lots - 2 Lots per Job.

\begin{tabular}{|c|c|c|c|c|c|c|c|}
\hline Performance measure & Policy & Limit $1^{\ddagger}$ & Limit 2 & Limit 3 & Limit 4 & Limit 5 & No Limit \\
\hline \multirow{6}{*}{$\begin{array}{c}\text { Shop Throughput Time } \\
\text { (time units) }\end{array}$} & TP1RP1* & 15.916 & 16.987 & 17.570 & 17.903 & 18.073 & 18.233 \\
\hline & TP2RP1** & 15.746 & 16.789 & 17.375 & 17.675 & 17.837 & 17.991 \\
\hline & TP3RP1*** & 15.175 & 16.095 & 16.608 & 16.869 & 17.021 & 17.144 \\
\hline & TP1RP2 & 15.724 & 16.847 & 17.508 & 17.858 & 18.053 & 18.233 \\
\hline & TP2RP2 & 15.580 & 16.669 & 17.309 & 17.641 & 17.819 & 17.991 \\
\hline & TP3RP2 & 15.038 & 16.014 & 16.556 & 16.845 & 17.003 & 17.144 \\
\hline \multirow{6}{*}{$\begin{array}{c}\text { Total Throughput Time } \\
\text { (time units) }\end{array}$} & TP1RP1* & 18.620 & 18.371 & 18.261 & 18.245 & 18.237 & 18.233 \\
\hline & TP2RP1** & 18.289 & 18.102 & 18.040 & 18.001 & 17.989 & 17.991 \\
\hline & TP3RP1*** & 17.316 & 17.197 & 17.165 & 17.143 & 17.148 & 17.144 \\
\hline & TP1RP2 & 17.945 & 18.039 & 18.120 & 18.167 & 18.202 & 18.233 \\
\hline & TP2RP2 & 17.714 & 17.810 & 17.905 & 17.937 & 17.961 & 17.991 \\
\hline & TP3RP2 & 16.889 & 17.009 & 17.067 & 17.096 & 17.122 & 17.144 \\
\hline \multirow{6}{*}{$\begin{array}{l}\text { Tardy } \\
(\%)\end{array}$} & TP1RP1* & 3.788 & 3.394 & 3.568 & 3.917 & 4.179 & 4.349 \\
\hline & TP2RP1** & 3.571 & 3.239 & 3.446 & 3.770 & 4.002 & 4.169 \\
\hline & TP3RP $1^{* * *}$ & 2.899 & 2.596 & 2.804 & 3.084 & 3.301 & 3.444 \\
\hline & TP1RP2 & 3.332 & 3.180 & 3.469 & 3.855 & 4.143 & 4.349 \\
\hline & TP2RP2 & 3.197 & 3.037 & 3.353 & 3.698 & 3.974 & 4.169 \\
\hline & TP3RP2 & 2.632 & 2.493 & 2.732 & 3.042 & 3.269 & 3.440 \\
\hline \multirow{6}{*}{$\begin{array}{l}\text { Tardiness } \\
\text { (time units) }\end{array}$} & TP1RP1* & 1.125 & 0.627 & 0.408 & 0.319 & 0.290 & 0.282 \\
\hline & TP2RP1** & 1.034 & 0.589 & 0.390 & 0.306 & 0.274 & 0.271 \\
\hline & TP3RP1*** & 0.824 & 0.473 & 0.315 & 0.245 & 0.220 & 0.219 \\
\hline & TP1RP2 & 0.763 & 0.483 & 0.349 & 0.293 & 0.277 & 0.282 \\
\hline & TP2RP2 & 0.726 & 0.461 & 0.338 & 0.281 & 0.265 & 0.271 \\
\hline & TP3RP2 & 0.615 & 0.391 & 0.279 & 0.228 & 0.213 & 0.219 \\
\hline
\end{tabular}

*Equivalent to TP1RP3; ** Equivalent to TP2RP3; *** Equivalent to TP3RP3; ${ }^{\ddagger}$ Tightest limit level on shop WIP 
Table A8: Results for the Transfer Policies (TP) and Release Policies (RP) with a Setup Factor of 5\% when Controlling the Number of Lots -3 Lots per Job.

\begin{tabular}{|c|c|c|c|c|c|c|c|}
\hline Performance measure & Policy & Limit $1^{\ddagger}$ & Limit 2 & Limit 3 & Limit 4 & Limit 5 & No Limit \\
\hline \multirow{6}{*}{$\begin{array}{c}\text { Shop Throughput Time } \\
\text { (time units) }\end{array}$} & TP1RP1* & 15.145 & 16.113 & 16.656 & 16.943 & 17.093 & 17.215 \\
\hline & TP2RP1** & 14.903 & 15.816 & 16.335 & 16.609 & 16.747 & 16.854 \\
\hline & TP3RP1*** & 14.115 & 14.895 & 15.326 & 15.548 & 15.658 & 15.753 \\
\hline & TP1RP2 & 15.086 & 16.079 & 16.641 & 16.936 & 17.087 & 17.215 \\
\hline & TP2RP2 & 14.852 & 15.788 & 16.329 & 16.600 & 16.744 & 16.854 \\
\hline & TP3RP2 & 14.077 & 14.879 & 15.313 & 15.544 & 15.656 & 15.753 \\
\hline \multirow{6}{*}{$\begin{array}{c}\text { Total Throughput Time } \\
\text { (time units) }\end{array}$} & TP1RP1* & 16.682 & 16.899 & 17.045 & 17.129 & 17.177 & 17.215 \\
\hline & TP2RP1** & 16.336 & 16.548 & 16.695 & 16.783 & 16.824 & 16.854 \\
\hline & TP3RP1*** & 15.265 & 15.479 & 15.611 & 15.681 & 15.717 & 15.753 \\
\hline & TP1RP2 & 16.550 & 16.837 & 17.022 & 17.120 & 17.169 & 17.215 \\
\hline & TP2RP2 & 16.224 & 16.501 & 16.686 & 16.771 & 16.821 & 16.854 \\
\hline & TP3RP2 & 15.195 & 15.450 & 15.591 & 15.676 & 15.715 & 15.753 \\
\hline \multirow{6}{*}{$\begin{array}{l}\text { Tardy } \\
(\%)\end{array}$} & TP1RP1* & 2.318 & 2.206 & 2.477 & 2.781 & 3.013 & 3.202 \\
\hline & TP2RP1 ** & 2.178 & 2.062 & 2.291 & 2.622 & 2.831 & 2.997 \\
\hline & TP3RP $1^{* * *}$ & 1.608 & 1.512 & 1.689 & 1.930 & 2.111 & 2.265 \\
\hline & TP1RP2 & 2.217 & 2.175 & 2.452 & 2.777 & 3.016 & 3.202 \\
\hline & TP2RP2 & 2.082 & 2.055 & 2.317 & 2.617 & 2.833 & 2.997 \\
\hline & TP3RP2 & 1.564 & 1.499 & 1.680 & 1.937 & 2.113 & 2.265 \\
\hline \multirow{6}{*}{$\begin{array}{l}\text { Tardiness } \\
\text { (time units) }\end{array}$} & TP1RP1* & 0.420 & 0.267 & 0.202 & 0.180 & 0.179 & 0.192 \\
\hline & TP2RP1** & 0.386 & 0.248 & 0.187 & 0.170 & 0.168 & 0.180 \\
\hline & TP3RP1*** & 0.288 & 0.185 & 0.137 & 0.122 & 0.122 & 0.133 \\
\hline & TP1RP2 & 0.374 & 0.249 & 0.198 & 0.179 & 0.179 & 0.192 \\
\hline & TP2RP2 & 0.344 & 0.234 & 0.185 & 0.168 & 0.168 & 0.180 \\
\hline & TP3RP2 & 0.268 & 0.177 & 0.134 & 0.122 & 0.122 & 0.133 \\
\hline
\end{tabular}

${ }^{*}$ Equivalent to TP1RP3; ** Equivalent to TP2RP3; *** Equivalent to TP3RP3; ${ }^{\ddagger}$ Tightest limit level on shop WIP 
Table A9: Results for the Transfer Policies (TP) and Release Policies (RP) with a Setup Factor of 5\% when Controlling the Number of Lots -4 Lots per Job.

\begin{tabular}{|c|c|c|c|c|c|c|c|}
\hline Performance measure & Policy & Limit $1^{\ddagger}$ & Limit 2 & Limit 3 & Limit 4 & Limit 5 & No Limit \\
\hline \multirow{6}{*}{$\begin{array}{c}\text { Shop Throughput Time } \\
\text { (time units) }\end{array}$} & TP1RP1* & 14.909 & 15.793 & 16.284 & 16.531 & 16.651 & 16.747 \\
\hline & TP2RP1** & 14.592 & 15.425 & 15.883 & 16.115 & 16.219 & 16.306 \\
\hline & TP3RP1*** & 13.685 & 14.374 & 14.730 & 14.914 & 15.007 & 15.074 \\
\hline & TP1RP2 & 14.848 & 15.761 & 16.261 & 16.534 & 16.649 & 16.747 \\
\hline & TP2RP2 & 14.558 & 15.406 & 15.872 & 16.112 & 16.219 & 16.306 \\
\hline & TP3RP2 & 13.651 & 14.367 & 14.725 & 14.908 & 15.009 & 15.074 \\
\hline \multirow{6}{*}{$\begin{array}{c}\text { Total Throughput Time } \\
\text { (time units) }\end{array}$} & TP1RP1* & 16.317 & 16.491 & 16.617 & 16.686 & 16.717 & 16.747 \\
\hline & TP2RP1** & 15.873 & 16.059 & 16.189 & 16.254 & 16.280 & 16.306 \\
\hline & TP3RP1*** & 14.676 & 14.863 & 14.963 & 15.019 & 15.052 & 15.074 \\
\hline & TP1RP2 & 16.176 & 16.432 & 16.589 & 16.686 & 16.715 & 16.747 \\
\hline & TP2RP2 & 15.794 & 16.027 & 16.176 & 16.253 & 16.279 & 16.306 \\
\hline & TP3RP2 & 14.612 & 14.852 & 14.957 & 15.013 & 15.054 & 15.074 \\
\hline \multirow{6}{*}{$\begin{array}{l}\text { Tardy } \\
(\%)\end{array}$} & TP1RP1* & 2.090 & 1.898 & 2.093 & 2.369 & 2.568 & 2.735 \\
\hline & TP2RP1 ** & 1.900 & 1.732 & 1.939 & 2.193 & 2.382 & 2.537 \\
\hline & TP3RP $1^{* * *}$ & 1.351 & 1.209 & 1.330 & 1.536 & 1.684 & 1.803 \\
\hline & TP1RP2 & 1.983 & 1.877 & 2.096 & 2.383 & 2.573 & 2.735 \\
\hline & TP2RP2 & 1.846 & 1.736 & 1.951 & 2.213 & 2.388 & 2.537 \\
\hline & TP3RP2 & 1.305 & 1.220 & 1.342 & 1.534 & 1.692 & 1.803 \\
\hline \multirow{6}{*}{$\begin{array}{l}\text { Tardiness } \\
\text { (time units) }\end{array}$} & TP1RP1* & 0.396 & 0.240 & 0.171 & 0.150 & 0.147 & 0.159 \\
\hline & TP2RP1** & 0.354 & 0.214 & 0.158 & 0.137 & 0.135 & 0.147 \\
\hline & TP3RP1*** & 0.251 & 0.155 & 0.110 & 0.095 & 0.095 & 0.103 \\
\hline & TP1RP2 & 0.347 & 0.222 & 0.168 & 0.148 & 0.147 & 0.159 \\
\hline & TP2RP2 & 0.319 & 0.205 & 0.168 & 0.138 & 0.136 & 0.147 \\
\hline & TP3RP2 & 0.234 & 0.151 & 0.109 & 0.095 & 0.095 & 0.103 \\
\hline
\end{tabular}

${ }^{*}$ Equivalent to TP1RP3; ** Equivalent to TP2RP3; *** Equivalent to TP3RP3; ${ }^{\ddagger}$ Tightest limit level on shop WIP 
Table A10: Results for the Transfer Policies (TP) and Release Policies (RP) with a Setup Factor of $5 \%$ when Controlling the Shop Load - 2 Lots per Job.

\begin{tabular}{|c|c|c|c|c|c|c|c|}
\hline Performance measure & Policy & Limit $1^{\ddagger}$ & Limit 2 & Limit 3 & Limit 4 & Limit 5 & No Limit \\
\hline \multirow{9}{*}{$\begin{array}{l}\text { Shop Throughput Time } \\
\text { (time units) }\end{array}$} & TP1RP1 & 14.789 & 16.109 & 16.987 & 17.519 & 17.838 & 18.233 \\
\hline & TP2RP1 & 14.661 & 15.953 & 16.784 & 17.315 & 17.622 & 17.991 \\
\hline & TP3RP1 & 14.243 & 15.411 & 16.138 & 16.590 & 16.846 & 17.144 \\
\hline & TP1RP2 & 14.603 & 16.006 & 16.919 & 17.486 & 17.817 & 18.233 \\
\hline & TP2RP2 & 14.493 & 15.866 & 16.736 & 17.278 & 17.605 & 17.991 \\
\hline & TP3RP2 & 14.114 & 15.318 & 16.096 & 16.561 & 16.825 & 17.144 \\
\hline & TP1RP3 & & & 16.773 & 17.418 & 17.784 & 18.233 \\
\hline & TP2RP3 & & 15.451 & 16.541 & 17.196 & 17.557 & 17.991 \\
\hline & TP3RP2 & & 15.003 & 15.942 & 16.485 & 16.793 & 17.144 \\
\hline \multirow{9}{*}{$\begin{array}{c}\text { Total Throughput Time } \\
\text { (time units) }\end{array}$} & TP1RP1 & 18.281 & 17.810 & 17.888 & 17.998 & 18.095 & 18.233 \\
\hline & TP2RP1 & 17.947 & 17.566 & 17.637 & 17.771 & 17.868 & 17.991 \\
\hline & TP3RP1 & 16.787 & 16.727 & 16.842 & 16.964 & 17.045 & 17.144 \\
\hline & TP1RP2 & 17.492 & 17.612 & 17.804 & 17.968 & 18.079 & 18.233 \\
\hline & TP2RP2 & 17.297 & 17.412 & 17.582 & 17.736 & 17.853 & 17.991 \\
\hline & TP3RP2 & 16.415 & 16.582 & 16.793 & 16.938 & 17.025 & 17.144 \\
\hline & TP1RP3 & & & 17.875 & 18.006 & 18.098 & 18.233 \\
\hline & TP2RP3 & & 17.295 & 17.535 & 17.740 & 17.852 & 17.991 \\
\hline & TP3RP3 & & 16.747 & 16.855 & 16.967 & 17.047 & 17.144 \\
\hline \multirow{9}{*}{$\begin{array}{l}\text { Tardy } \\
(\%)\end{array}$} & TP1RP1 & 3.483 & 2.646 & 2.531 & 2.892 & 3.462 & 4.349 \\
\hline & TP2RP1 & 3.336 & 2.516 & 2.410 & 2.799 & 3.314 & 4.169 \\
\hline & TP3RP1 & 2.621 & 1.992 & 1.905 & 2.265 & 2.743 & 3.440 \\
\hline & TP1RP2 & 3.640 & 2.820 & 2.678 & 3.003 & 3.515 & 4.349 \\
\hline & TP2RP2 & 3.520 & 2.720 & 2.586 & 2.879 & 3.362 & 4.169 \\
\hline & TP3RP2 & 2.790 & 2.129 & 2.027 & 2.335 & 2.773 & 3.440 \\
\hline & TP1RP3 & & & 2.474 & 2.924 & 3.491 & 4.349 \\
\hline & TP2RP3 & & 2.281 & 2.267 & 2.757 & 3.335 & 4.169 \\
\hline & TP3RP3 & & 2.003 & 1.873 & 2.229 & 2.754 & 3.440 \\
\hline \multirow{9}{*}{$\begin{array}{l}\text { Tardiness } \\
\text { (time units) }\end{array}$} & TP1RP1 & 1.906 & 0.834 & 0.471 & 0.318 & 0.265 & 0.282 \\
\hline & TP2RP1 & 1.754 & 0.782 & 0.441 & 0.302 & 0.254 & 0.271 \\
\hline & TP3RP1 & 1.234 & 0.601 & 0.349 & 0.239 & 0.200 & 0.219 \\
\hline & TP1RP2 & 1.127 & 0.653 & 0.415 & 0.305 & 0.263 & 0.282 \\
\hline & TP2RP2 & 1.084 & 0.622 & 0.394 & 0.289 & 0.251 & 0.271 \\
\hline & TP3RP2 & 0.855 & 0.491 & 0.315 & 0.230 & 0.198 & 0.219 \\
\hline & TP1RP3 & & & 0.445 & 0.303 & 0.254 & 0.282 \\
\hline & TP2RP3 & & 0.704 & 0.393 & 0.277 & 0.241 & 0.271 \\
\hline & TP3RP3 & & 0.731 & 0.386 & 0.252 & 0.203 & 0.219 \\
\hline
\end{tabular}

\footnotetext{
${ }^{\ddagger}$ Tightest limit level on shop WIP
} 
Table A11: Results for the Transfer Policies (TP) and Release Policies (RP) with a Setup Factor of $5 \%$ when Controlling the Shop Load - 3 Lots per Job.

\begin{tabular}{|c|c|c|c|c|c|c|c|}
\hline Performance measure & Policy & Limit $1^{\ddagger}$ & Limit 2 & Limit 3 & Limit 4 & Limit 5 & No Limit \\
\hline \multirow{9}{*}{$\begin{array}{c}\text { Shop Throughput Time } \\
\text { (time units) }\end{array}$} & TP1RP1 & 14.393 & 15.548 & 16.273 & 16.708 & 16.945 & 17.215 \\
\hline & TP2RP1 & 14.152 & 15.281 & 15.973 & 16.380 & 16.603 & 16.854 \\
\hline & TP3RP1 & 13.548 & 14.491 & 15.054 & 15.375 & 15.560 & 15.753 \\
\hline & TP1RP2 & 14.207 & 15.465 & 16.217 & 16.676 & 16.932 & 17.215 \\
\hline & TP2RP2 & 14.027 & 15.207 & 15.934 & 16.353 & 16.592 & 16.854 \\
\hline & TP3RP2 & 13.451 & 14.442 & 15.023 & 15.354 & 15.553 & 15.753 \\
\hline & TP1RP3 & & & 16.056 & 16.589 & 16.889 & 17.215 \\
\hline & TP2RP3 & & 14.774 & 15.713 & 16.250 & 16.533 & 16.854 \\
\hline & TP3RP2 & & 14.116 & 14.867 & 15.289 & 15.525 & 15.753 \\
\hline \multirow{9}{*}{$\begin{array}{c}\text { Total Throughput Time } \\
\text { (time units) }\end{array}$} & TP1RP1 & 17.176 & 16.892 & 16.949 & 17.064 & 17.122 & 17.215 \\
\hline & TP2RP1 & 16.660 & 16.520 & 16.606 & 16.704 & 16.769 & 16.854 \\
\hline & TP3RP1 & 15.375 & 15.413 & 15.530 & 15.617 & 15.681 & 15.753 \\
\hline & TP1RP2 & 16.604 & 16.747 & 16.890 & 17.029 & 17.112 & 17.215 \\
\hline & TP2RP2 & 16.280 & 16.410 & 16.570 & 16.684 & 16.760 & 16.854 \\
\hline & TP3RP2 & 15.167 & 15.350 & 15.498 & 15.598 & 15.677 & 15.753 \\
\hline & TP1RP3 & & & 16.999 & 17.060 & 17.129 & 17.215 \\
\hline & TP2RP3 & & 16.311 & 16.507 & 16.670 & 16.748 & 16.854 \\
\hline & TP3RP3 & & 15.457 & 15.549 & 15.638 & 15.696 & 15.753 \\
\hline \multirow{9}{*}{$\begin{array}{l}\text { Tardy } \\
(\%)\end{array}$} & TP1RP1 & 2.918 & 2.131 & 1.937 & 2.242 & 2.611 & 3.202 \\
\hline & TP2RP1 & 2.656 & 1.958 & 1.817 & 2.070 & 2.459 & 2.997 \\
\hline & TP3RP1 & 1.932 & 1.377 & 1.294 & 1.514 & 1.820 & 2.265 \\
\hline & TP1RP2 & 3.018 & 2.258 & 2.057 & 2.288 & 2.647 & 3.202 \\
\hline & TP2RP2 & 2.826 & 2.113 & 1.951 & 2.151 & 2.479 & 2.997 \\
\hline & TP3RP2 & 2.029 & 1.493 & 1.372 & 1.561 & 1.846 & 2.265 \\
\hline & TP1RP3 & & & 1.932 & 2.239 & 2.650 & 3.202 \\
\hline & TP2RP3 & & 1.781 & 1.708 & 2.063 & 2.467 & 2.997 \\
\hline & TP3RP3 & & 1.472 & 1.290 & 1.519 & 1.853 & 2.265 \\
\hline \multirow{9}{*}{$\begin{array}{l}\text { Tardiness } \\
\text { (time units) }\end{array}$} & TP1RP1 & 1.393 & 0.611 & 0.329 & 0.227 & 0.182 & 0.192 \\
\hline & TP2RP1 & 1.212 & 0.555 & 0.308 & 0.206 & 0.170 & 0.180 \\
\hline & TP3RP1 & 0.783 & 0.379 & 0.217 & 0.145 & 0.120 & 0.133 \\
\hline & TP1RP2 & 0.862 & 0.482 & 0.295 & 0.214 & 0.181 & 0.192 \\
\hline & TP2RP2 & 0.795 & 0.446 & 0.278 & 0.200 & 0.168 & 0.180 \\
\hline & TP3RP2 & 0.579 & 0.323 & 0.199 & 0.140 & 0.121 & 0.133 \\
\hline & TP1RP3 & & & 0.349 & 0.216 & 0.177 & 0.192 \\
\hline & TP2RP3 & & 0.513 & 0.270 & 0.188 & 0.160 & 0.180 \\
\hline & TP3RP3 & & 0.490 & 0.257 & 0.162 & 0.125 & 0.133 \\
\hline
\end{tabular}

\footnotetext{
${ }^{\ddagger}$ Tightest limit level on shop WIP
} 
Table A12: Results for the Transfer Policies (TP) and Release Policies (RP) with a Setup Factor of $5 \%$ when Controlling the Shop Load - 4 Lots per Job.

\begin{tabular}{|c|c|c|c|c|c|c|c|}
\hline Performance measure & Policy & Limit $1^{\ddagger}$ & Limit 2 & Limit 3 & Limit 4 & Limit 5 & No Limit \\
\hline \multirow{9}{*}{$\begin{array}{c}\text { Shop Throughput Time } \\
\text { (time units) }\end{array}$} & TP1RP1 & 14.181 & 15.271 & 15.933 & 16.317 & 16.527 & 16.747 \\
\hline & TP2RP1 & 13.900 & 14.925 & 15.552 & 15.909 & 16.109 & 16.306 \\
\hline & TP3RP1 & 13.164 & 14.005 & 14.498 & 14.775 & 14.924 & 15.074 \\
\hline & TP1RP2 & 14.034 & 15.184 & 15.887 & 16.288 & 16.516 & 16.747 \\
\hline & TP2RP2 & 13.783 & 14.869 & 15.512 & 15.889 & 16.095 & 16.306 \\
\hline & TP3RP2 & 13.089 & 13.968 & 14.481 & 14.766 & 14.918 & 15.074 \\
\hline & TP1RP3 & & & 15.715 & 16.212 & 16.481 & 16.747 \\
\hline & TP2RP3 & & 14.447 & 15.313 & 15.794 & 16.053 & 16.306 \\
\hline & TP3RP2 & & 13.664 & 14.340 & 14.698 & 14.887 & 15.074 \\
\hline \multirow{9}{*}{$\begin{array}{c}\text { Total Throughput Time } \\
\text { (time units) }\end{array}$} & TP1RP1 & 16.669 & 16.467 & 16.534 & 16.617 & 16.676 & 16.747 \\
\hline & TP2RP1 & 16.087 & 15.990 & 16.091 & 16.182 & 16.243 & 16.306 \\
\hline & TP3RP1 & 14.694 & 14.775 & 14.885 & 14.972 & 15.019 & 15.074 \\
\hline & TP1RP2 & 16.210 & 16.319 & 16.478 & 16.588 & 16.665 & 16.747 \\
\hline & TP2RP2 & 15.800 & 15.918 & 16.055 & 16.170 & 16.233 & 16.306 \\
\hline & TP3RP2 & 14.552 & 14.729 & 14.872 & 14.963 & 15.015 & 15.074 \\
\hline & TP1RP3 & & & 16.566 & 16.634 & 16.687 & 16.747 \\
\hline & TP2RP3 & & 15.839 & 16.031 & 16.166 & 16.239 & 16.306 \\
\hline & TP3RP3 & & 14.850 & 14.928 & 14.993 & 15.027 & 15.074 \\
\hline \multirow{9}{*}{$\begin{array}{c}\text { Tardy } \\
\text { (\%) }\end{array}$} & TP1RP1 & 2.664 & 1.889 & 1.737 & 1.937 & 2.271 & 2.735 \\
\hline & TP2RP1 & 2.371 & 1.695 & 1.571 & 1.794 & 2.091 & 2.537 \\
\hline & TP3RP1 & 1.632 & 1.158 & 1.064 & 1.237 & 1.478 & 1.803 \\
\hline & TP1RP2 & 2.698 & 1.984 & 1.829 & 1.988 & 2.292 & 2.735 \\
\hline & TP2RP2 & 2.496 & 1.825 & 1.676 & 1.861 & 2.122 & 2.537 \\
\hline & TP3RP2 & 1.700 & 1.228 & 1.122 & 1.264 & 1.494 & 1.803 \\
\hline & TP1RP3 & & & 1.712 & 1.980 & 2.312 & 2.735 \\
\hline & TP2RP3 & & 1.577 & 1.508 & 1.775 & 2.116 & 2.537 \\
\hline & TP3RP3 & & 1.265 & 1.081 & 1.240 & 1.495 & 1.803 \\
\hline \multirow{9}{*}{$\begin{array}{l}\text { Tardiness } \\
\text { (time units) }\end{array}$} & TP1RP1 & 1.188 & 0.526 & 0.287 & 0.187 & 0.152 & 0.159 \\
\hline & TP2RP1 & 0.996 & 0.453 & 0.252 & 0.170 & 0.138 & 0.147 \\
\hline & TP3RP1 & 0.610 & 0.301 & 0.169 & 0.114 & 0.094 & 0.103 \\
\hline & TP1RP2 & 0.748 & 0.410 & 0.251 & 0.177 & 0.150 & 0.159 \\
\hline & TP2RP2 & 0.678 & 0.372 & 0.229 & 0.166 & 0.138 & 0.147 \\
\hline & TP3RP2 & 0.469 & 0.259 & 0.157 & 0.109 & 0.093 & 0.103 \\
\hline & TP1RP3 & & & 0.292 & 0.181 & 0.147 & 0.159 \\
\hline & TP2RP3 & & 0.428 & 0.230 & 0.159 & 0.133 & 0.147 \\
\hline & TP3RP3 & & 0.411 & 0.211 & 0.129 & 0.098 & 0.103 \\
\hline
\end{tabular}

${ }^{\ddagger}$ Tightest limit level on shop WIP 